This article has been published in a revised form in Macroeconomic Dynamics https://doi.org/10.1017/S1365100515000814. This version is free to view and download for private research and study only. Not for re-distribution, re-sale or use in derivative works. OCambridge University Press. 


\title{
The Simple Dynamics of Public Debt with Productive Public Goods
}

\author{
Pierre-Richard Agénor* and Devrim Yilmaz** \\ Final version: May 9, 2016 \\ Forthcoming, Macroeconomic Dynamics
}

\begin{abstract}
This paper analyzes the dynamics of public debt in a simple two-period overlapping generations model of endogenous growth with productive public goods. Alternative fiscal rules are defined, with particular attention devoted to the golden rule. Conditions under which multiple equilibria may emerge are characterized. The analysis is then extended to consider the case of partial depreciation, an endogenous risk premium, an endogenous primary surplus rule, a generalized golden rule, a nonseparable utility function, and network externalities. If network effects are sufficiently strong, an increase in public investment may shift the economy from a low-growth equilibrium to a steady state characterized by both higher public debt ratios and higher output growth. This shift may enhance welfare as well. These results illustrate the importance of preserving, even in a context of fiscal retrenchment, the allocation of resources to specific types of public investment.
\end{abstract}

JEL Classification Numbers: H54, H63, O41

*University of Manchester and Centre for Growth and Business Cycle Research; ** Kingston University. We are grateful to seminar participants at the University of York, the University of Manchester, and the Australian National University, as well as two anonymous referees and the Associate Editor, for many helpful comments on a previous draft. The working paper version of this article, which contains a more detailed introduction and conclusion, is available upon request. 


\section{Introduction}

The global financial crisis led governments all around the world to implement massive bailouts of financial institutions and large fiscal stimulus packages. Combined with a sharp reduction in tax revenues, itself resulting from sharp contractions in economic activity, this policy response led to growing fiscal imbalances in many industrial countries (see International Monetary Fund (2014, Table 1.1)). ${ }^{1}$ Although in recent years fiscal deficits have fallen in some countries, debt-to-GDP ratios have remained stubbornly high. $^{2}$

Given this context, the issue of public debt sustainability naturally returned to the fore of the policy agenda in many industrial countries. But in contrast to previous episodes of fiscal consolidation, policymakers proved to be clearly aware of the importance of sustained economic growth for restoring fiscal balance and of the need to avoid measures, such as cuts in public investment or support for $R \& D$, that would weaken the economy's supply side. This was a key motivation for the emphasis on the need to invest in the provision of productive services, especially infrastructure, in the composition of stimulus packages. Fiscal policy in industrial countries faces therefore a double dilemma: restoring public debt sustainability while making sure that growth is promoted through productive investment.

Although less acute given that the impact of the financial crisis on fiscal deficits was not as severe - this dilemma is also present in many middle-income countries where, to begin with, stocks of infrastructure assets are much lower than in industrial countries.

From an analytical perspective, the key issues are the extent to which public investment affects growth and fiscal sustainability — without crowding out private investmentand the degree to which these effects depend on how investment is financed. ${ }^{3}$ The

\footnotetext{
${ }^{1}$ Public debt had actually started to accumulate well before the crisis in some of these countries, mostly because of rising spending. But the increase in outlays in the aftermath of the global recession was rapid and large, as some countries borrowed at record levels. Revenue losses and increases in interest payments were also important factors.

${ }^{2}$ In the largest developing countries, the impact of the crisis on fiscal deficits was not as severe as in advanced economies. Moreover, due to sustained growth, debt ratios actually fell in some of these countries.

${ }^{3}$ The second issue is related to the debate on whether debt-financed spending on productive public goods "pays for itself", in the sense of stimulating sufficiently economic growth to raise revenues, while ensuring that the debt-to-output ratio converges to a stable value.
} 
dynamics of public debt and economic growth have been studied in numerous contributions, including Chalk (2000), De la Croix and Michel (2002), Futagami and Shibata (2003), Brauninger (2005), Annichiarico and Giammarioli (2008), Fernández-Huertas and Vidal (2010), and Michel et al. (2010). Chalk (2000) for instance analyzed the sustainability of bond-financed deficits in a two-period overlapping generations (OLG) model and established conditions under which a growth rate larger than the interest rate is a necessary, but not sufficient, condition to ensure the sustainability of a permanent budget deficit. Using also an OLG model, De la Croix and Michel (2002) studied the dynamic effects of the introduction of public debt and derived sustainability conditions. Fernández-Huertas and Vidal (2010) study fiscal sustainability in an economy where the engine of growth is human capital formation.

However, none of these contributions accounts for the provision of productive public goods or the dynamics of public capital. This is important because although public debt accumulation associated with an increase in spending on productive goods subtracts resources from private capital accumulation, exerting a crowding out effect, it exerts simultaneously a crowding in effect. Intuitively, as long as the growth in public debt (which depends on the share of spending allocated to productive public goods and the share financed by issuing bonds) is not too large, sustained economic growth may be sufficient to prevent unsustainable fiscal imbalances.

A small strand of the literature, which includes Turnovsky (1997, 2004), Greiner and Semmler (2000), Ghosh and Mourmouras (2004), Ghosh and Nolan (2007), Greiner (2007, 2011), Futagami et al. (2008), Yakita (2008), Greiner and Flaschel (2010), Arai (2011), Agénor and Yilmaz (2011), Greiner (2012), Minea and Villieu (2012), and Teles and Mussolini (2014), has indeed focused on the dynamics of productive spending, public debt, and growth. This paper contributes to this literature in several ways. First, unlike Ghosh and Nolan (2007), Greiner (2007, 2011), Greiner and Flaschel (2010), and Agénor and Yilmaz (2011), whose analysis dwells on representative agent intertemporal models with a unique balanced growth equilibrium, we consider, as in Yakita (2008) and Arai (2011), an OLG framework. Because the dynamics of consumption are simpler in basic OLG models with log-linear utility, the study of public debt sustainability is somewhat easier - and so is the analytical characterization of multiple equilibria. 
Second, and in contrast to the latter two papers, the tax rate is not endogenous. In those models, as in Brauninger (2005), the government fixes its public deficit objective, either as the deficit itself in proportion to output or as the share of the budget deficit to be financed by debt (a criterion consistent with the Maastricht Treaty), and chooses the tax rate residually from the budget constraint.

In our basic framework, the tax rate, the public spending plan and the structure of public deficit financing are exogenous, while the budget deficit is endogenous. As a result, the focus of our analysis is budget realizations, rather than budget objectives. The sustainability of public debt is thus discussed in terms of the composition of government spending, rather than a critical level of fiscal deficits. In addition, unlike Yakita (2008) and Arai (2011), we also account for unproductive spending and transfers to households, with the latter creating a direct feedback effect between public debt accumulation, changes in private savings, and private capital formation. Our basic framework yields a dynamic system that is recursive, and thus simpler to analyze than Yakita's, in particular. We also consider extensions that have not been studied before in the literature, such as an endogenous risk premium and nonlinearities associated with the productivity effects of public capital. The latter is particularly important from the perspective of designing fiscal adjustment programs aimed at promoting growth while ensuring public debt sustainability.

Our main results can be summarized as follows. First, as in some previous studies, we show that the steady-state relationship between output growth and the debt-private capital ratio is unambiguously negative under the golden rule, implying that, with multiple equilibria, the low- (high-) debt equilibrium is associated with a higher (lower) growth rate. However, despite this negative relationship, we also show that an increase in the share of investment in infrastructure has an ambiguous effect on long-run growth. On the one hand, it raises the debt-private capital ratio, which tends to lower growth; on the other, it raises the public-private capital ratio, both directly and indirectly. If the elasticity of output with respect to public capital is sufficiently high, the steady-state growth rate of output will increase. We are able to establish this result because, unlike previous studies, an explicit distinction is made in our model between the elasticities of output with respect to labor and public capital. 
Second, we show that with an endogenous risk premium (which rises with the debtprivate capital ratio, to capture default risk), the higher the sensitivity of that premium to the debt-private capital ratio, the more likely it is that multiple equilibria will emerge if the steady-state value of that ratio is less than unity; in contrast, if the debt-private capital ratio is too high, it is more likely that there may be no equilibria. This result is important to understand the (unstable) dynamics of public debt in recent sovereign debt crises in Europe.

Third, we introduce network externalities associated with public capital, to capture nonlinearities in its productivity. Until a sufficiently complex network is built, public capital has a relatively low (and constant) marginal productivity. Once the main parts of a network are put together, small additional increases in infrastructure investment are associated with strong productivity gains; and beyond another level, the marginal productivity gains induced by additional investments tend to slow down. We find that although the qualitative features of the dynamics of the debt-private capital ratio do not change, a steady-state characterized by high growth and high public debt can now emerge if network effects are sufficiently strong. A large enough increase in the share of output allocated to public investment may therefore shift the economy from a low-growth, low-debt equilibrium to an equilibrium characterized by both higher debt and higher growth. This shift may be welfare-enhancing as well, particularly so if in addition to its productivity effects public capital generates some utility benefits. Again, this result has important implications for the ongoing debate on fiscal consolidation. ${ }^{4}$

The paper continues as follows. Section 2 presents our basic framework. Section 3 studies the dynamics of the model and establishes conditions under which multiple equilibria may emerge. Several extensions are considered in Section 4, namely, partial depreciation, an endogenous risk premium, an endogenous primary surplus rule, a generalized golden rule, and network effects associated with public capital. The last section of the paper offers some concluding remarks.

\footnotetext{
${ }^{4}$ It is worth noting that our analysis, given its focus on growth and supply-side effects, has abstracted from another important issue in the current debate on public investment - its impact on aggregate demand and employment in the short run.
} 


\section{A Basic Framework}

Consider an OLG economy where a single good is produced and individuals live for two periods, adulthood and old age. The good can be either consumed in the period it is produced or stored to yield capital at the beginning of the following period. Each individual is endowed with one unit of time in each period of life. In adulthood time is devoted entirely to market work, whereas in old age time is allocated entirely to leisure. In the first period of life income consists of both wages and a government transfer, and serves to finance consumption and saving for old age. Savings can be held in the form of physical capital or government bonds. Endowments at time $t=0$ consist of initial stocks of physical capital and government bonds, which are held by an initial generation of retirees. There are no altruistically-motivated intergenerational bequests, implying that Ricardian equivalence does not hold. ${ }^{5}$

Population is constant. In addition to individuals, the economy is populated by firms and an infinitely-lived government. Firms produce goods using private capital, labor, and public capital as inputs. The government invests in a productive good and spends on some unproductive services, including transfers to households. It provides its services free of charge. It taxes only the wage income of adults and issues one-period bonds to finance its deficit. All markets clear in equilibrium.

\subsection{Households}

Expected lifetime utility at the beginning of period $t$ is

$$
U_{t}=\ln c_{t}^{t}+\frac{\ln c_{t+1}^{t}}{1+\rho}
$$

where $c_{t+j}^{i}$ denotes consumption of generation $i$ individuals at date $t+j$ and $\rho>0$ the discount rate.

Period-specific budget constraints are given by

$$
\begin{aligned}
c_{t}^{t}+s_{t} & =(1-\tau) w_{t}+x_{t}, \\
c_{t+1}^{t} & =\left(1+r_{t+1}\right) s_{t},
\end{aligned}
$$

\footnotetext{
${ }^{5}$ In fact, even with bequests, Ricardian equivalence would not hold here, due to the presence (as discussed later) of distortionary income taxation.
} 
where $w_{t}$ is the wage rate, $\tau \in(0,1)$ the tax rate, $x_{t}$ a government transfer (which the household takes as given when solving its optimization problem), $r_{t+1}$ the rental rate of private capital, and $s_{t}$ saving. To simplify matters, transfers and interest income of old agents are not taxed. ${ }^{6}$

The household's consolidated budget constraint is

$$
c_{t}^{t}+\frac{c_{t+1}^{t}}{1+r_{t+1}}=(1-\tau) w_{t}+x_{t}
$$

\section{$2.2 \quad$ Firms}

There is a continuum of identical firms, indexed by $i \in(0,1)$. They produce a single nonstorable good, which is used either for consumption or investment. Production requires the use of private inputs, labor and private capital (which firms rent from the currently old agents), and public capital.

The production function of firm $i$ takes the form

$$
Y_{t}^{i}=\left(K_{t}^{I}\right)^{\alpha}\left(K_{t}^{P}\right)^{\eta}\left(N_{t}^{i}\right)^{\beta}\left(K_{t}^{P, i}\right)^{1-\beta}
$$

where $K_{t}^{P, i}$ denotes the firm-specific stock of capital, $K_{t}^{P}=\int_{0}^{1} K_{t}^{P, i} d i$ the aggregate private capital stock, $K_{t}^{I}$ the stock of public capital, $N_{t}^{i}$ the number of workers employed by firm $i, \alpha, \eta>0$, and $\beta \in(0,1)$. Thus, production exhibits constant returns to scale in firm-specific inputs, $N_{t}^{i}$ and $K_{t}^{P, i}$. Public capital in infrastructure is exogenous to each firm's production process and affects all individual producers in the same way. There is also an Arrow-Romer type externality associated with aggregate private capital. The magnitudes of these externalities are measured by $\alpha$ and $\eta$, respectively. In line with much of the empirical evidence reviewed in Bom and Ligthart (2014), we impose $\alpha<1$.

Markets for both private capital and labor are competitive. Each firm's objective is to maximize profits, $\Pi_{t}^{i}$, with respect to labor services and private capital, taking

\footnotetext{
${ }^{6}$ For simplicity, we also abstract from government transfers to the old generation (as in Annichiarico and Giammarioli (2008) or Michel et al. (2010) for instance) and issues associated with social security. Note also that we do not endogenize labor supply; doing so by incorporating leisure additively in (1) would not alter qualitatively our results.
} 
$K_{t}^{I}$ and $K_{t}^{P}$ as given:

$$
\max _{N_{t}^{i}, K_{t}^{P, i}} \Pi_{t}^{i}=Y_{t}^{i}-\left(r_{t}+\delta^{P}\right) K_{t}^{P, i}-w_{t} N_{t}^{i}
$$

where $r_{t}$ is the rental rate of private capital and $\delta^{P} \in(0,1)$ the depreciation rate.

Profit maximization yields, in a symmetric equilibrium,

$$
w_{t}=\beta Y_{t} / \bar{N}, \quad r_{t}+\delta^{P}=(1-\beta) Y_{t} / K_{t}^{P} .
$$

where $\bar{N}=\int_{0}^{1} N_{t}^{i} d i$ is total population, which is normalized to unity in what follows. The second expression equates the user cost of capital to the gross marginal physical product of private capital.

Because the number of firms is normalized to 1, aggregate output is given by

$$
Y_{t}=\int_{0}^{1} Y_{t}^{i} d i=\left(k_{t}^{I}\right)^{\alpha}\left(K_{t}^{P}\right)^{1+\alpha-\beta+\eta},
$$

where $k_{t}^{I}=K_{t}^{I} / K_{t}^{P}$ is the public-private capital ratio. To ensure balanced growth (linearity of output in the private capital stock) requires the following assumption: ${ }^{7}$

Assumption 1: $\eta=\beta-\alpha$.

Under Assumption 1, (7) yields aggregate output as

$$
Y_{t}=\left(k_{t}^{I}\right)^{\alpha} K_{t}^{P}
$$

\subsection{Government}

The government taxes adults at the constant rate $\tau$ and spends a total of $G_{t}^{I}$ on productive public goods and $G_{t}^{U}$ on other (unproductive) items, including transfers. The government budget constraint is

$$
B_{t+1}=\left(1+i_{t}\right) B_{t}+G_{t}^{I}+G_{t}^{U}-\tau w_{t}
$$

where $i_{t}$ is the gross rate of return on government bonds. The expression $G_{t}^{I}+G_{t}^{U}-\tau w_{t}$ represents therefore the primary budget deficit.

\footnotetext{
${ }^{7}$ If $\eta=0$ then $\alpha=\beta$, as in various contributions, stemming from Barro (1990). However, this case is somewhat misleading, as discussed later. Note also that there is a scale effect in production, which can be eliminated by specifying the Arrow-Romer externality in terms of the ratio of the aggregate private capital stock to the size of the population.
} 
Shares of spending are assumed initially to be constant fractions of revenues:

$$
G_{t}^{h}=v_{h} \tau w_{t}, \quad h=I, U
$$

where $v_{h} \in(0,1)$. Combining (9) and (10) therefore yields

$$
B_{t+1}=\left(1+i_{t}\right) B_{t}-\left[1-\left(v_{I}+v_{U}\right)\right] \tau w_{t}
$$

Thus, with a primary balance rule, $v_{I}+v_{U}=1$, all taxes are spent on non-interest outlays, and debt remains constant at zero if $B_{0}=0$; otherwise, it grows autonomously as long as $i_{t}>0$. In contrast, with a primary surplus rule, $v_{I}+v_{U}<1$, the government uses a fraction of its tax revenues to service its debt, and debt will fall over time if the interest factor $1+i_{t}$ is not too high.

Assuming full depreciation, the law of motion of the public capital stock in infrastructure is given by ${ }^{8}$

$$
K_{t+1}^{I}=G_{t}^{I}
$$

\subsection{Market-Clearing and Equilibrium}

Assuming full depreciation of private capital $\left(\delta^{P}=1\right)$, the market-clearing condition requires private savings be equal to tomorrow's stock of physical assets plus the stock of government bonds:

$$
K_{t+1}^{P}+B_{t+1}=s_{t}
$$

On the basis of these equations, the following definitions can be provided.

Definition 1: A competitive equilibrium in this economy is a sequence of prices $\left\{w_{t}, r_{t}, i_{t}\right\}_{t=0}^{\infty}$, consumption and savings $\left\{c_{t}^{t}, c_{t+1}^{t}, s_{t}\right\}_{t=0}^{\infty}$, public and private capital stocks $\left\{K_{t+1}^{P}, K_{t+1}^{I}\right\}_{t=0}^{\infty}$, government debt $\left\{B_{t+1}\right\}_{t=0}^{\infty}$, a constant tax rate $\tau$ and constant spending shares $v_{I}, v_{U}$, such that, given the initial capital stocks $K_{0}^{P}$ and $K_{0}^{I}>0$ and the initial stock of public debt $B_{0}>0$, individuals maximize utility, firms maximize profits, and the product market clears.

\footnotetext{
${ }^{8} \mathrm{~A}$ more general specification would be to assume that the production of public capital requires combining both the spending flow on productive goods and the existing stock of public capital, so that $K_{t+1}^{I}=\left(G_{t}^{I}\right)^{\mu}\left(K_{t}^{I}\right)^{1-\mu}$, with $\mu \in(0,1)$. Our results would remain qualitatively similar. Note also that we do not consider the issue of efficiency of public investment, which could be captured, as in Agénor (2010) for instance, by multiplying $G_{t}^{I}$ in (12) by a parameter that takes a value lower than unity.
} 
Definition 2: A balanced growth equilibrium is a competitive equilibrium in which $c_{t}^{t}, c_{t+1}^{t}, w_{t}, Y_{t}, K_{t}^{P}, K_{t}^{I}$, and $B_{t}$ all grow at the constant rate $1+\gamma$ and the rate of return on private capital $r_{t}$ and the interest rate on government bonds $i_{t}$ are both constant over time.

By implication, the public debt-private capital ratio and the public-private capital ratio are both constant in equilibrium.

In what follows transfers to each individual are assumed to be given as a fraction of unproductive spending per capita; thus, $x_{t}=\chi G_{t}^{U} / \bar{N}$, where $\chi \in(0,1)$. Using this assumption, and given the normalization $\bar{N}=1$, it is straightforward to establish that in equilibrium savings are given by

$$
s_{t}=\sigma\left[(1-\tau)+v_{U} \tau \chi\right] \beta Y_{t},
$$

where $\sigma=1 /(2+\rho)<1$ is the individual, before-tax savings rate. ${ }^{9}$ Thus, given the log-linear utility function used in (1), the savings rate does not depend on the rental rate of capital, $r_{t+1}$.

Assuming that physical and financial assets are perfect substitutes implies the no arbitrage condition $1+i_{t}=1+r_{t}$. Thus, using (6) and (8), and given full depreciation of private capital,

$$
1+i_{t}=\frac{(1-\beta) Y_{t}}{K_{t}^{P}}=(1-\beta)\left(k_{t}^{I}\right)^{\alpha} .
$$

Changes in the interest rate on government bonds are therefore endogenously related to changes in the public-private capital ratio, thereby creating interdependence between the dynamics of public debt and capital accumulation.

\section{Dynamics and Fiscal Rules}

We begin by deriving the dynamics of the debt-private capital ratio and the growth rate of output. Sustainability of fiscal policy is defined in the process, in relation to the existence of a balanced growth equilibrium. We then consider three alternative fiscal rules (a primary balance rule, a primary surplus rule, and a golden rule) and

\footnotetext{
${ }^{9}$ From (4), $x_{t}=\chi G_{t}^{U}$, and from (6) and (10), $x_{t}=\chi v_{U} \tau w_{t}=\chi v_{U} \tau \beta Y_{t}$. Substituting this result in (4) and using again (6) yields $c_{t}^{t}+c_{t+1}^{t} /\left(1+r_{t+1}\right)=\left[(1-\tau)+v_{U} \tau \chi\right] \beta Y_{t}$. In standard fashion, the optimization problem yields the Euler equation $c_{t+1}^{t} / c_{t}^{t}=1+r_{t+1} /(1+\rho)$, which can be substituted in the consolidated budget constraint to give $c_{t}^{t}=[(1+\rho) /(2+\rho)]\left[(1-\tau)+v_{U} \tau \chi\right] \beta Y_{t}$. Using $(2)$ and the expression for $x_{t}$ derived earlier yields equation (14).
} 
examine the conditions under which multiple equilibria, all characterized by a positive and constant public debt-private capital ratio, may emerge.

\subsection{Debt and Growth Dynamics}

To analyze the dynamics of the economy, begin by substituting (10) in (12) and use (6) to give

$$
K_{t+1}^{I}=v_{I} \tau \beta Y_{t}
$$

Substituting (6), (11) and (14) in (13) yields

$$
K_{t+1}^{P}=\Lambda_{1} Y_{t}-\left(1+i_{t}\right) B_{t}
$$

where

$$
\Lambda_{1}=\left\{\sigma\left[(1-\tau)+v_{U} \tau \chi\right]+\left[1-\left(v_{I}+v_{U}\right)\right] \tau\right\} \beta,
$$

is the aggregate, after-tax savings rate, whose sign depends on the fiscal rule in place.

Using (8) and (15), and with $b_{t}=B_{t} / K_{t}^{P}$ defined as the public debt-private capital ratio, equation (17) can be written as

$$
\frac{K_{t+1}^{P}}{K_{t}^{P}}=\left(k_{t}^{I}\right)^{\alpha}\left[\Lambda_{1}-(1-\beta)\right] b_{t} .
$$

Similarly, from (8) and (16),

$$
\frac{K_{t+1}^{I}}{K_{t}^{I}}=v_{I} \tau \beta\left(\frac{Y_{t}}{K_{t}^{I}}\right)=v_{I} \tau \beta\left(k_{t}^{I}\right)^{\alpha-1} .
$$

Dividing (20) by (19) gives

$$
k_{t+1}^{I}=\frac{v_{I} \tau \beta}{\Lambda_{1}-(1-\beta) b_{t}} .
$$

Equation (21) determines the dynamics of the public-private capital ratio as a function solely of the debt-private capital ratio. ${ }^{10}$ For it to yield a positive value of $k^{I}$ in a steady state with positive debt, the following necessary (although not sufficient) restriction is imposed:

\footnotetext{
${ }^{10}$ It can easily be established that, if as noted earlier public capital accumulation is specificed as $K_{t+1}^{I}=\left(G_{t}^{I}\right)^{\mu}\left(K_{t}^{I}\right)^{1-\mu}$, with $\mu \in(0,1)$ instead of $(12), k_{t+1}^{I}$ in (21) would also depend on $k_{t}^{I}$. However, the system would remain recursive.
} 
Assumption 2: $\Lambda_{1}>0$.

Because $\Lambda_{1}$ depends on how government spending is allocated, whether Assumption 2 is automatically satisfied or not depends on the nature of the fiscal rule. As can be inferred from (18), with a primary balance rule or a primary surplus rule, $\Lambda_{1}$ is always positive. With a golden rule, however, this is not necessarily the case, as shown later.

Now, to determine the dynamics of public debt, note that equation (11) can be written as, using (6),

$$
\frac{B_{t+1}}{B_{t}}=1+i_{t}-\left[1-\left(v_{I}+v_{U}\right)\right] \tau \beta\left(\frac{Y_{t}}{K_{t}^{P}}\right)\left(\frac{K_{t}^{P}}{B_{t}}\right),
$$

that is, using (8) and (15),

$$
\frac{B_{t+1}}{B_{t}}=\left[(1-\beta)-\Lambda_{2} b_{t}^{-1}\right]\left(k_{t}^{I}\right)^{\alpha},
$$

where

$$
\Lambda_{2}=\left[1-\left(v_{I}+v_{U}\right)\right] \tau \beta
$$

Dividing (22) by (19) gives

$$
b_{t+1}=\frac{(1-\beta) b_{t}-\Lambda_{2}}{\Lambda_{1}-(1-\beta) b_{t}}=F\left(b_{t}\right),
$$

from which it can be established that

$$
F^{\prime}=\frac{(1-\beta)\left(\Lambda_{1}-\Lambda_{2}\right)}{\left[\Lambda_{1}-(1-\beta) \tilde{b}\right]^{2}}, \quad F^{\prime \prime}=\frac{2(1-\beta) F^{\prime}}{\Lambda_{1}-(1-\beta) \tilde{b}},
$$

where $\tilde{b}$ is the steady-state value of the debt-to-private capital ratio.

From the definitions of $\Lambda_{1}$ and $\Lambda_{2}$ in (18) and (23), it can be established that $\Lambda_{1}-$ $\Lambda_{2}>0$. Thus, $F^{\prime}>0$. Given Assumption 2, to ensure that the public-private capital ratio is positive requires that the debt-private capital ratio be less than $\Lambda_{1} /(1-\beta)$. If so then $F^{\prime \prime}$ is also positive, which implies that the transition curve $F()$ is convex, as illustrated in Figure 1. ${ }^{11}$

The model consists therefore of (21) and (24). It is recursive: equation (24) determines the evolution of $b_{t}$, which can be substituted in (21) to determine the evolution

\footnotetext{
${ }^{11}$ The figure assumes that $-\Lambda_{2} / \Lambda_{1}>0$, which turns out to be the case for some of the fiscal rules considered later. Note that the transition curve becomes steeper as $-\Lambda_{2} / \Lambda_{1}$ rises.
} 
of $k_{t}^{I}$. The fundamental reason for this property, as can be inferred from (8), (19), and (22), is that both the private capital stock and the stock of public debt are linear in the output-capital ratio. In addition, because the term $\left(k_{t}^{I}\right)^{\alpha}$ drops out when solving for the reduce form of the system, the parameter $\alpha$ has no effect on the dynamics of $b_{t}$ and $k_{t}^{I}$.

We can now provide a definition of fiscal sustainability. ${ }^{12}$

Definition 3: A fiscal policy rule defined by a vector $\left(v_{I}, v_{U}, \chi, \tau\right)$ of budgetary parameters is sustainable if, for given structural parameters $(\alpha, \beta, \sigma)$ and an initial value $b_{0}>0$, it is associated with a balanced growth equilibrium with $\tilde{b}>0$.

Put differently, and by implication of Definition 2, a fiscal policy rule is sustainable if a balanced growth path exists, because in that case the debt-private capital ratio (given an initial level $b_{0}$ ) always converges to some positive, finite level in the long run. ${ }^{13}$ Note that this definition does not exclude the possibility of multiple equilibrium growth paths.

Now, the economy's balanced growth path is given by ${ }^{14}$

$$
1+\gamma_{t+1}=\frac{Y_{t+1}}{Y_{t}}=\left(v_{I} \tau \beta\right)^{\alpha}\left[\Lambda_{1}-(1-\beta) b_{t}\right]^{1-\alpha}
$$

which implies a negative relationship between the debt-private capital ratio and the growth rate of output. On the one hand, an increase in $b_{t}$ raises the public-private capital ratio, which tends to promote growth; on the other, it lowers the rate of private capital accumulation, which tends to hamper growth. Given our parameter assumptions (namely, $\alpha<1$ ), and the linearity of the aggregate production function in the private capital stock, the crowding-out effect dominates the crowding-in effect and the net impact on growth of higher debt is (all things equal, specifically for $v_{I}$ given) always negative.

\footnotetext{
${ }^{12}$ In the standard definition of fiscal (or debt) sustainability, a fiscal policy is said to be sustainable if the present value of future primary surpluses equals the current level of debt (see, for instance, Collignon (2012)). Put differently, the budget must be balanced in present value terms to rule out Ponzi games. The definition provided here is broader and in line with the recent analytical literature; see for instance, Yakita (2008). Moreover, in a model as simple as the one considered here (with, in particular, log-linear utility), it encompasses the no-Ponzi game condition.

${ }^{13}$ In general, $\tilde{b}$ can be either positive or negative. However, from an economic point of view a positive value of government debt is more realistic.

${ }^{14}$ To determine this result, first write equation (8) for $t+1$, so that $Y_{t+1}=\left(k_{t+1}^{I}\right)^{\alpha} K_{t+1}^{P}$, or equivalently, using (17), $Y_{t+1}=\left(k_{t+1}^{I}\right)^{\alpha}\left[\Lambda_{1} Y_{t}-\left(1+i_{t}\right) B_{t}\right]$. Substituting (15) in this expression yields $Y_{t+1}=\left(k_{t+1}^{I}\right)^{\alpha}\left[\Lambda_{1}-(1-\beta) b_{t}\right] Y_{t}$. Substituting (21) in this expression yields (25).
} 
Setting $b_{t+1}=b_{t}$ in (24) implies that the steady-state debt-private capital ratio is the solution of the quadratic equation

$$
(1-\beta) \tilde{b}^{2}-\left[\Lambda_{1}-(1-\beta)\right] \tilde{b}-\Lambda_{2}=0
$$

where $\Lambda_{1}-(1-\beta) \lessgtr 0$ in general. From $(21)$, the steady-state public-private capital ratio is given by

$$
\tilde{k}^{I}=\frac{v_{I} \tau \beta}{\Lambda_{1}-(1-\beta) \tilde{b}},
$$

which again describes a convex relationship between $\tilde{k}^{I}$ and $\tilde{b}$. Similarly, from (25) the equilibrium growth rate of output is

$$
1+\gamma=\left(v_{I} \tau \beta\right)^{\alpha}\left[\Lambda_{1}-(1-\beta) \tilde{b}\right]^{1-\alpha}
$$

Depending on the values of $\Lambda_{1}$ and $\Lambda_{2}$, the model may exhibit no equilibrium, a single equilibrium, or two equilibria. And given that both $\Lambda_{1}$ and $\Lambda_{2}$ depend on the fiscal policy rule, we need now to consider alternative specifications of these rules.

\subsection{Alternative Fiscal Rules}

\subsubsection{Primary Balance Rule}

With a primary balance rule, $v_{I}+v_{U}=1$; from (18) and (23), $\Lambda_{1}=\sigma\left[(1-\tau)+v_{U} \tau \chi\right] \beta>$ 0 and $\Lambda_{2}=0$. Thus, Assumption 2 is automatically satisfied. Ignoring the trivial solution $\tilde{b}=0$, equation $(26)$ boils down to ${ }^{15}$

$$
\tilde{b}=\frac{\Lambda_{1}-(1-\beta)}{1-\beta}=\frac{\Lambda_{1}}{1-\beta}-1
$$

which is positive as long as $\Lambda_{1}-(1-\beta)>0$. In turn, this condition requires $(1-\tau)+$ $v_{U} \tau \chi>(1-\beta) / \sigma \beta$, or equivalently, with $v_{I}=1-v_{U}$,

$$
v_{I}<\left.v_{I}^{C}\right|_{v_{I}+v_{U}=1}=1+(\tau \chi)^{-1}\left\{1-\tau-\frac{1-\beta}{\sigma \beta}\right\} .
$$

With $\tilde{b}$ given by (29), equations (27) and (28) imply that the public-private capital ratio and the growth rate are given by $\tilde{k}^{I}=v_{I} \tau \beta /(1-\beta)$, and $1+\gamma=\left(v_{I} \tau \beta\right)^{\alpha}(1-\beta)^{1-\alpha}$,

\footnotetext{
${ }^{15}$ With a primary balance rule, and given that $\Lambda_{2}=0$, the origin of the transition curve is at 0 in Figure 1.
} 
which are always positive. From (15), $1+\tilde{\imath}=1+\gamma$, or equivalently the rate of return to capital must be equal to the growth rate of output to ensure that the debt-private capital (or, equivalently, the debt-output) ratio does not explode. These results can be summarized in the following proposition.

Proposition 1. With a primary balance rule, and positive transfers to households, a steady-state equilibrium with positive debt, a positive public-private capital ratio, and positive growth exists if the share of government spending allocated to investment is not too large.

Intuitively, with a primary balance rule, interest payments alone drive the growth in public debt. However, the no-arbitrage condition implies a positive relationship between the interest rate on government bonds and the public-private capital ratio; if that ratio grows too fast, because the fraction of resources allocated to investment in infrastructure is too high, public debt will grow too fast compared to private capital and output. Convergence cannot be achieved.

To get a practical sense of the conditions under which (30) holds, consider the following calibration (see Table 1 for a summary). In line with standard empirical estimates of the labor elasticity of output, the value of $\beta$ is set at 0.7 . Fernández-Huertas and Vidal (2010) for instance use the same value. Studies such as Turnovsky (2004) and Annichiarico and Giammarioli (2008) for instance use a value of 0.25 for the tax rate; here, to account for the fact that only labor is taxed in the model, we divide this rate by the labor share. Thus, $\tau=0.25 / 0.7=0.36$. To estimate the savings rate, as defined in the model, we adjust the actual data to account for the proportion of unemployed households and indirect savings through pension contributions by employed workers and employer contributions; using OECD data for major industrial countries (available at http://stats.oecd.org/), this gives an estimate of $\sigma=0.56$. Based on OECD data for the cash benefits component of social expenditure, government transfers to households can be estimated at 12.4 percent of GDP in 2013 for the same group of countries, whereas Inderst (2013) estimates that the share of public investment in infrastructure for industrial countries was about 1.3 percent of GDP in recent years. From (6), $w=\beta Y$, whereas from (10), $G^{I}=v_{I} \tau w$; thus, the actual $v_{I}$ can be estimated as $v_{I}=(G / Y) / \tau \beta=0.013 / 0.25=5.2$ percent. Moreover, from (10), under 
a primary balance rule we also have $G^{U}=\left(1-v_{I}\right) \tau w$; this gives therefore the share of unproductive spending (or, more precisely here, spending other than infrastructure investment) in total revenues as $v_{U}=0.948$. By implication, the share of transfers in total unproductive spending can be estimated as $\chi=0.124 /(0.25 \cdot 0.948)=0.52$. Using the calibrated values of $\tau, \chi, \beta$ and $\sigma$, the value implied by the right-hand side of (30) is 0.34 , which implies indeed that $v_{I}<\left.v_{I}^{C}\right|_{v_{I}+v_{U}=1}$.

\subsubsection{Primary Surplus Rule}

With a primary surplus rule, $v_{I}+v_{U}<1$, and from (18), (23) and Assumption 1, $\Lambda_{1}, \Lambda_{2}>0$. In fact, regardless of the sign of $\Lambda_{1}-(1-\beta)$, equation (26) yields one positive and one negative solution for $\tilde{b} .{ }^{16}$ There are no multiple equilibria in that case. Moreover, it can be verified that the admissible equilibrium is always unstable. In terms of Figure 1, this can be illustrated by noting that, as before, $F^{\prime}, F^{\prime \prime}>0$. In addition, with $\Lambda_{1}, \Lambda_{2}>0, F(0)=-\Lambda_{2} / \Lambda_{1}<0$. Thus, the transition curve $F\left(b_{t}\right)$ intersects the 45-degree line only once, from below. Intuitively, if the initial value of debt is lower than the (unique) equilibrium value, the policy rule drives that debt to zero in finite time. Conversely, if public debt is initially higher than its equilibrium value, the policy is unable to tame the unstable dynamics associated with interest payments; as a result, the debt-public capital ratio grows without bounds.

\subsubsection{Golden Rule}

With an (interest-inclusive) golden rule, $v_{U}=1$, all public investment and interest payments are financed by borrowing, and $\Lambda_{1}=\left\{\sigma[(1-\tau)+\tau \chi]-v_{I} \tau\right\} \beta \gtrless 0, \Lambda_{2}=$ $-v_{I} \tau \beta<0 .{ }^{17,18}$ However, the nature of the equilibria depends on the sign of $\Lambda_{1}-(1-\beta)$.

\footnotetext{
${ }^{16}$ This is a direct implication of Descartes' rule of signs, according to which the number of positive real roots of a polynomial is bounded by the number of changes in sign of the sequence of its coefficients. The discriminant of $(26)$ is $\Delta=\left[\Lambda_{1}-(1-\beta)\right]^{2}+4(1-\beta) \Lambda_{2}$, which is always positive. Because $\sqrt{\Delta}>\Lambda_{1}-(1-\beta)$, the positive solution is $\left[\Lambda_{1}-(1-\beta)+\sqrt{\Delta}\right] / 2(1-\beta)$.

${ }^{17}$ Note that in that case, as implied by (10), investment spending is still defined in terms of a fraction of tax revenues. As a share of output, government investment is simply $\tau v_{I}$.

${ }^{18}$ We consider an interest-inclusive golden rule in the benchmark case on the ground that if investment today is going to benefit future generations, then the whole burden of repaying the debt, which includes interest payments, should be borne by future generations as well. In the next section a more general rule, which considers only partial bond financing of interest payments, is considered.
} 
If $\Lambda_{1}-(1-\beta)>0$ (a necessary condition for which is $\Lambda_{1}>0$, as noted in Assumption 2 ), equation (26) can yield zero, one, or two positive solutions for $\tilde{b}$. In contrast, with $\Lambda_{1}-(1-\beta)<0$, there are no positive solutions to $(26) .{ }^{19}$ Intuitively, in that case even if the aggregate savings rate is positive $\left(\Lambda_{1}>0\right)$, it is not large enough to ensure positive private capital accumulation because the fraction of the economy's savings claimed by the government (through the accumulation of public debt) is too high.

The condition for $\Lambda_{1}-(1-\beta)>0$ is now $\sigma[(1-\tau)+\tau \chi]-v_{I} \tau>(1-\beta) / \beta$, or equivalently

$$
v_{I}<\left.v_{I}^{C}\right|_{v_{U}=1} ^{1}=\tau^{-1}\left\{\sigma[(1-\tau)+\tau \chi]-\frac{1-\beta}{\beta}\right\} .
$$

Using the values provided earlier for $\tau, \sigma, \chi$ and $\beta$ yields $\left.v_{I}^{C}\right|_{v_{U}=1} ^{1}=0.1$, which implies indeed that $v_{I}<\left.v_{I}^{C}\right|_{v_{U}=1} ^{1}$. However, this restriction on $v_{I}$ is necessary, but not sufficient, to generate multiple equilibria. To do so there is a second critical value of $v_{I}$ below which multiple equilibria can emerge, determined by $\Lambda_{1}=(1-\beta)+$ $2 \sqrt{-\Lambda_{2}(1-\beta)}$, or equivalently

$$
\left\{\sigma[(1-\tau)+\tau \chi]-v_{I} \tau\right\} \beta-(1-\beta)-2 \sqrt{v_{I} \tau \beta(1-\beta)}=0
$$

This expression cannot be solved analytically for $v_{I}$. Let $\left.v_{I}^{C}\right|_{v_{U}=1} ^{2}$ denote the threshold value of $v_{I}$ implied by (31); then it must be that $\left.v_{I}^{C}\right|_{v_{U}=1} ^{2}<\left.v_{I}^{C}\right|_{v_{U}=1} ^{1}$. This is proved in a simple manner in Figure 2. Let $h\left(v_{I}\right)=\left\{\sigma[(1-\tau)+\tau \chi]-v_{I} \tau\right\} \beta$; it is linear in $v_{I}$, with a negative slope $h^{\prime}=-\tau \beta$. Let also $g\left(v_{I}\right)=(1-\beta)+2 \sqrt{v_{I} \tau \beta(1-\beta)}$; it is an increasing, concave function of $v_{I}$, with $g(0)=1-\beta$. The critical value $\left.v_{I}^{C}\right|_{v_{U}=1} ^{1}$ is determined at the intersection of $h\left(v_{I}\right)$ with the line $1-\beta$, at Point $A$, whereas the critical value $\left.v_{I}^{C}\right|_{v_{U}=1} ^{2}$ is determined at the intersection of $h\left(v_{I}\right)$ and $g\left(v_{I}\right)$, at Point $B .^{20}$

For $v_{I} \in\left(\left.v_{I}^{C}\right|_{v_{U}=1} ^{2},\left.v_{I}^{C}\right|_{v_{U}=1} ^{1}\right)$ there is no admissible equilibrium (consistent with Definitions 1-3), whereas for $v_{I}=\left.v_{I}^{C}\right|_{v_{U}=1} ^{2}$ there is a single equilibrium. In Figure

\footnotetext{
${ }^{19}$ More precisely, the existence and the number of equilibria depends on the sign of $\Delta=\left[\Lambda_{1}-(1-\right.$ $\beta)]^{2}+4(1-\beta) \Lambda_{2}$, which (given that $\Lambda_{2}<0$ ) is in general ambiguous. If $\Delta>0$, there are two positive values of $\tilde{b}$ that will satisfy (26), whereas with $\Delta=0$, the equilibrium is unique. With $\Delta<0$, there is no equilibrium with real values. After some manipulations, the necessary condition for the existence of multiple equilibria can be expressed as $\Lambda_{1}>(1-\beta)+2\left[-\Lambda_{2}(1-\beta)\right]^{0.5}$. With $\Lambda_{1}-(1-\beta)<0$, this condition cannot be fulfilled.

${ }^{20}$ Figure 2 assumes that $h(0)=\sigma[(1-\tau)+\tau \chi] \beta>1-\beta$. This condition is satisfied for a large range of reasonable values for the underlying parameters.
} 
1, this corresponds to the point at which the transition curve $F\left(b_{t}\right)$ is tangent to the 45-degree line, at Point $A$; in Figure 2, this corresponds to Point $B$, where $h\left(v_{I}\right)$ and $g\left(v_{I}\right)$ intersect. For $v_{I}<\left.v_{I}^{C}\right|_{v_{U}=1} ^{2}$ there are multiple equilibria. ${ }^{21}$

These results can be summarized as follows.

Proposition 2. With a golden rule, and given that $\left.v_{I}^{C}\right|_{v_{U}=1} ^{2}<\left.v_{I}^{C}\right|_{v_{U}=1} ^{1}$, there are no equilibria with a non-negative steady-state value of the public debt-private capital ratio if $v_{I} \in\left(\left.v_{I}^{C}\right|_{v_{U}=1} ^{2},\left.v_{I}^{C}\right|_{v_{U}=1} ^{1}\right)$, a single equilibrium if $v_{I}=\left.v_{I}^{C}\right|_{v_{U}=1} ^{2}$, and multiple equilibria if $v_{I}<\left.v_{I}^{C}\right|_{v_{U}=1} ^{2}$.

In Figure 2 we also compare the threshold levels of the investment share under the primary balance and the golden rules. From the condition used to establish (30), let $z\left(v_{I}\right)=\sigma\left[(1-\tau)+\left(1-v_{I}\right) \tau \chi\right] \beta$. This function is also linear in $v_{I}$, with a slope $z^{\prime}=-\sigma \tau \chi \beta<0$ and $z(0)=h(0)$. The threshold value $\left.v_{I}^{C}\right|_{v_{I}+v_{U}=1}$ is obtained at the intersection of $z\left(v_{I}\right)$ and the line $1-\beta$, as shown at point $C$ in the figure. Because $\left|z^{\prime}\right|<\left|h^{\prime}\right|$, the figure also shows (quite intuitively) that the threshold value of the investment share for an equilibrium with a positive steady-state solution of the debtprivate capital ratio is unambiguously higher with a primary balance rule.

The possibility of multiple (nontrivial) equilibria in the case of the golden rule under the condition $\Lambda_{1}-(1-\beta)>0$, is illustrated in Figure 1. If $v_{I}$ is too high (that is, $\left.v_{I}>\left.v_{I}^{C}\right|_{v_{U}=1} ^{2}\right)$, the transition curve $F\left(b_{t}\right)$ is located entirely above the 45-degree line and there is no equilibrium. Put differently, if the golden rule calls for investing a fraction $\tau v_{I}$ of output that is too large, the economy cannot reach a steady state: debt grows faster than the stock of public capital, and this implies that the debt-private capital ratio explodes. An overambitious, debt-financed program of public capital accumulation is not sustainable.

The figure also shows that there is a single equilibrium at Point $A$, and two equilibria at Points $B$ and $B^{\prime}$. Inspection of these equilibria, together with (27) and (28), yields the following result.

Proposition 3. When multiple steady-state equilibria exist, the equilibrium with the smaller (larger) public debt-private capital ratio is stable (unstable) and is associated

\footnotetext{
${ }^{21}$ A general borrowing "rule," in which the government borrows to finance either higher investment or unproductive spending, could also be defined by setting $v_{I}+v_{U}>1$. However, it is easy to verify that the nature of the solution to the model (namely, the conditions for generating multiple equilibria, this time in terms of $\left.v_{I}+v_{U}\right)$ is qualitatively similar to what is obtained under the golden rule.
} 
with a lower (larger) public-private capital ratio and a higher (lower) growth rate of output.

The negative relationship between the debt-private capital ratio and the growth rate of output, which can be directly inferred from (28), results from the fact that the crowding-out effect of public debt always dominates the productivity effect of public capital. $^{22}$ By implication of Proposition 3, the economy can attain the high steady state only if it starts there. If the initial debt-private capital ratio is at $b_{0}^{1}$ for instance, or at any point located below $b_{M}$ (corresponding to Point $B^{\prime}$ ), the economy will converge over time toward the low-debt, high-growth equilibrium $B$, which is characterized by equality between the growth rates of both capital stocks, output, and public debt. In contrast, if the economy starts at any point located above $b_{M}$, such as $b_{0}^{2}$, it will move over time away from the high-debt, low-growth equilibrium. The growth in public debt always exceeds the growth in the private capital stock, implying that their ratio increases continuously. In that sense, the fiscal policy is unsustainable; public investment must be cut sufficiently to ensure that the transition curve shifts down, in such a way that it intersects the 45-degree line to the right of point $C$; if so, the economy will begin to converge toward the low-debt, high-growth equilibrium. Put differently, if the initial debt is not too high (below $b_{M}$ ), the existing fiscal policy is sustainable, and movements along the transition curve will lead to a low-debt steady state; if the initial debt is too high (above $b_{M}$ ), a policy change, involving a downward shift in the transition curve, is required to make the fiscal stance sustainable. ${ }^{23}$ The

\footnotetext{
${ }^{22}$ In turn, as noted earlier, this is due to the linearity of the production function (8) with respect to private capital and the fact that $\alpha<1$. If there is crowding out, the effect of the reduction in the private capital stock always dominates the effect of an increase in the public capital stock-despite the fact that the former magnifies the increase in the public-private capital ratio.

${ }^{23}$ Note that with the general borrowing "rule" referred to earlier, according to which the government issues debt to finance both investment and unproductive spending $\left(v_{I}+v_{U}>1\right)$, the adjustment needed to ensure sustainability could involve cuts only in the latter component. However, if the initial debt ratio is well above $b_{M}$, cuts in both types of outlays may be inevitable. Alternatively, the initial debt level could be cut instantly to a level below $b_{M}$ either through debt cancellation, debt writedown, or unilateral default (assuming that the latter does not incur significant costs). In fact, if the incompressible level of public expenditure related to both current spending (on schools, the police, and courts for instance) and capital investment is high, a combination of expenditure reduction and debt cancelation may well be necessary to ensure that the fiscal adjustment is large enough to guarantee that the initial position of the economy puts it on a convergent path toward the high-growth, low-debt equilibrium. These results may be a good illustration of Greece's recent predicament.
} 
value $b_{M}$ is therefore the maximum initial debt-private capital ratio consistent with sustainability.

Another way to illustrate the possibility of multiple equilibrium values in the public debt-private capital ratio under the golden rule is as follows. Defining $p(\tilde{b})=(1-\beta) \tilde{b}^{2}$ and $q\left(\tilde{b}, v_{I}\right)=\left[\Lambda_{1}-(1-\beta)\right] \tilde{b}+\Lambda_{2}$, equation $(26)$ can be rewritten as

$$
p(\tilde{b})=q\left(\tilde{b}, v_{I}\right)
$$

with $p^{\prime}>0, q_{\tilde{b}} \gtrless 0$ if $\Lambda_{1}-(1-\beta) \gtrless 0$, and $q_{v_{I}}<0$.

Function $p(\tilde{b})$ is a parabola with a minimum at $\tilde{b}=0$, whereas function $q\left(\tilde{b}, v_{I}\right)$ is linear in $\tilde{b}$ and has an ambiguous slope; it also intersects the horizontal axis at a positive value of $\tilde{b}$, as long as $v_{I}$ is strictly positive. Both curves are shown in Figure 3 and alternative outcomes illustrated. It is immediately obvious that if $\Lambda_{1}-(1-\beta)<0$ a condition that is more likely to occur if $v_{I}$ is high - there cannot be an equilibrium where $p(\tilde{b})=q\left(\tilde{b}, v_{I}\right)$. If $\Lambda_{1}-(1-\beta)>0, q\left(\tilde{b}, v_{I}\right)$ is positively sloped and all three cases illustrated in Figure 1 may occur; there may be no equilibrium, a single equilibrium (Point $A$ ), or two equilibria (Points $B$ and $B^{\prime}$ ). For two (nontrivial) equilibria to emerge, $v_{I}$ must be smaller than the value that it takes at Point $A$, to ensure that $\Lambda_{1}=$ $\sigma(1-\tau) \beta-\Lambda_{2}$ is larger and $q\left(\tilde{b}, v_{I}\right)$ steeper. Thus, $q\left(\tilde{b}, v_{I}\right)$ rotates counterclockwise and shifts up at the same time. By implication, there can be neither a single equilibrium nor multiple equilibria if the investment program calls for a value of $v_{I}$ that is too high, because a higher value of $v_{I}$ shifts $q\left(\tilde{b}, v_{I}\right)$ downward and makes it flatter, whereas it has no effect on $p(\tilde{b})$.

Thus, the results with a golden rule are consistent with those obtained in studies that analyze the dynamics of public debt in endogenous growth models without public capital (such as Futagami and Shibata (2003) and Brauninger (2005)) and with public capital (such as Futagami et al. (2008) and Yakita (2008)): the low-debt steady state is characterized by high growth, and conversely for the high-debt equilibrium. Even though in the present setting government debt has a crowding-in effect as well, it is not large enough to offset the crowding-out effect on private savings and capital accumulation.

However, even though the growth rate of output and the public debt-private capital 
ratio are inversely related - not only in the steady state, but during the transition as well, as implied by (25) - public debt itself is endogenous. As a result, an increase in the share of investment $v_{I}$, in particular, has in general an ambiguous effect on growth. On the one hand, it raises the debt-private capital ratio, which tends to lower growth. On the other, it raises the public-private capital ratio, both directly and indirectly, as implied by (27). By implication, as can be inferred from (28), the steady-state growth rate of output may increase following a rise in $v_{I}$ if $\alpha$, the elasticity of output with respect to public capital, is sufficiently high.

This result can be illustrated graphically by extending Figure 1 to represent the downward-sloping curve linking $1+\gamma_{t+1}$ and $b_{t}$ (equation (25)) in an additional quadrant, as in Figure 4. This curve, referred to as $\Xi\left(b_{t}\right)$ in the lower panel of the figure, has a concave shape. Suppose that the initial position of the economy is at Point $B .{ }^{24}$ An increase in $v_{I}$ shifts the transition curve for $b_{t}$ (which does not depend on $\alpha$ ) upward in the upper quadrant, and raises the low steady-state value of that variable, from $B$ to $C$. Curve $\Xi\left(b_{t}\right)$ shifts upward in the lower quadrant, so initially growth unambiguously increases; however, as $b_{t}$ starts increasing towards its new, higher equilibrium value, the crowding-out effect creates a downward movement along $\Xi\left(b_{t}\right)$; the growth rate begins falling. Whether the end result is a higher or lower steady-state growth rate cannot be ascertained a priori and depends on $\alpha$. If $\alpha$ is high, the economy will move from $D^{\prime}$ to $D^{\prime \prime}$ where the growth rate is higher than initially. In contrast, if $\alpha$ is low, the economy may end up at $D^{\prime \prime \prime}$, where growth is lower than at Point $D .{ }^{25}$

This analysis brings out another important point. Inspection of the threshold values of the investment share under the primary balance and golden rules shows that neither one of these values depends on $\alpha$. This differs from most contributions in the literature based on representative agent and OLG models, such as Futagami et al. (2008), Yakita (2008), Arai (2011), Greiner (2012), and Minea and Villieu (2012), where that elasticity is set equal, in standard Barro (1990) fashion, to the labor elasticity of output. Put

\footnotetext{
${ }^{24}$ If the economy is initially at $B^{\prime}$ (the high-debt equilibrium), it cannot converge to a new equilibrium, given the movement of the transition curve in this experiment.

${ }^{25}$ Of course, if the increase in $v_{I}$ is financed by a cut in unproductive spending (such that $d v_{I}+d v_{U}=$ $0)$, the adverse effect on the debt-private capital ratio vanishes and the increase in $v_{I}$ would have an unambiguously positive effect on growth. However, as long as public borrowing is used, at least in part, to finance investment the ambiguity highlighted in the foregoing discussion will continue to hold.
} 
differently, the magnitude of the elasticity of output with respect to public capital plays no role in whether multiple equilibria may emerge (it does not affect the slope of the transition curve), and, as long as it is less than unity, in whether the growth rate of output and the debt-private capital ratio are positively or negatively related in the steady state. ${ }^{26}$ However, as the above experiment illustrates, it matters significantly when it comes to assessing the long-run effects on economic growth of a change in investment spending on infrastructure. ${ }^{27}$

\section{Extensions}

We now consider several extensions of the basic framework: partial depreciation of public and private capital, an endogenous risk premium on government debt, an endogenous primary surplus rule, a more general golden rule (in which only a fraction of public investment and interest payments are financed by debt accumulation), and network externalities associated with public capital in the production technology. ${ }^{28}$

\subsection{Partial Depreciation}

Under partial depreciation of private and public capital, equations (12) and (13) are replaced by

$$
\begin{gathered}
K_{t+1}^{I}=G_{t}^{I}+\left(1-\delta^{G}\right) K_{t}^{I}, \\
K_{t+1}^{P}+B_{t+1}=s_{t}+\left(1-\delta^{P}\right) K_{t}^{P},
\end{gathered}
$$

where $\delta^{P}, \delta^{G} \in(0,1)$. For simplicity, the no-arbitrage condition is now specified as $i_{t}=r_{t}+\delta^{P}$; thus, from (6), equation (15) continues to hold.

\footnotetext{
${ }^{26}$ As can be inferred from (8), in the particular case where $\alpha=1$ for instance, $Y_{t}=K_{t}^{I}$ and the crowding-out effect of public debt disappears; in that case, the debt-private capital ratio and output growth are positively related. The same result would hold with $\alpha>1$. As noted earlier, much of the (linear) empirical evidence suggests that $\alpha<1$ - except for the case of network externalities, which is discussed later.

${ }^{27}$ Teles and Mussolini (2014) also find that it is possible for an increase in productive government spending to raise the steady-state values of both the growth rate and the debt-to-output ratio - even though they also assume that that elasticity of output with respect to public capital is equal to the labor elasticity of output. However, as a result, the role of that elasticity cannot be clearly identified.

${ }^{28}$ In Appendix 1 we consider another extension, a nonseparable utility function. However, because explicit analytical solutions cannot be derived in that case, only an intuitive discussion is provided.
} 
The equation that determines the dynamics of the level of public debt, (22), remains the same. As shown in Appendix 1, The dynamic system in $b_{t}$ and $k_{t}^{I}$ is now given by

$$
\begin{aligned}
k_{t+1}^{I} & =\frac{v_{I} \tau \beta+\left(1-\delta^{G}\right)\left(k_{t}^{I}\right)^{1-\alpha}}{\Lambda_{1}-(1-\beta) b_{t}+\left(1-\delta^{P}\right)\left(k_{t}^{I}\right)^{-\alpha}}, \\
b_{t+1} & =\frac{(1-\beta) b_{t}-\Lambda_{2}}{\Lambda_{1}-(1-\beta) b_{t}+\left(1-\delta^{P}\right)\left(k_{t}^{I}\right)^{-\alpha}} .
\end{aligned}
$$

Thus, the system is no longer recursive; this is mainly because the public and private capital stocks are no longer linear in the output-private capital ratio. The evolution of $b_{t}$ and $k_{t}^{I}$ must be determined jointly. Equations (34) and (35) represent a highly nonlinear system, whose steady-state solution is given in Appendix 1. As also shown there, depending not only on how low $\delta^{G}$ and $\delta^{P}$ are (compared to the benchmark case of $\delta^{G}=\delta^{P}=1$ ), but also on the sign of $\delta^{G}-\delta^{P}$, more than two equilibria may emerge. To characterize these equilibria a numerical analysis is needed.

In the particular case where only private capital depreciates fully in one period $\left(\delta^{P}=1, \delta^{G}<1\right)$, equations (34) and (35) become

$$
\begin{gathered}
k_{t+1}^{I}=\frac{v_{I} \tau \beta+\left(1-\delta^{G}\right)\left(k_{t}^{I}\right)^{1-\alpha}}{\Lambda_{1}-(1-\beta) b_{t}}, \\
b_{t+1}=F\left(b_{t}\right),
\end{gathered}
$$

where $F\left(b_{t}\right)$ is defined in (24). Thus, with partial depreciation of public capital only, the system remains recursive, and the transition curve for $b_{t}$ continues to be independent of $\alpha$. As before, multiple equilibria can emerge. However, the dynamics of $b_{t}$ and $k_{t}^{I}$ are no longer independent of $\alpha$; and the steady-state growth rate of output, now equal to,

$$
1+\gamma=\left[v_{I} \tau \beta+\left(1-\delta^{G}\right)\left(\tilde{k}^{I}\right)^{1-\alpha}\right]^{\alpha}\left[\Lambda_{1}-(1-\beta) \tilde{b}\right]^{1-\alpha}
$$

may no longer be negatively related with public debt. In contrast to the case where $\delta^{G}=1$, an increase in the debt-private capital ratio does not necessarily raise the public-private capital ratio; this can be verified, as shown in Appendix 1, by applying the implicit function theorem to the steady-state solution of (36). But if it does, the growth-promoting effect of higher debt may be magnified, given the extra term $\left(1-\delta^{G}\right)\left(\tilde{k}^{I}\right)^{1-\alpha}$ in (38). And this effect may be large enough to dominate the crowdingout effect on the rate of private capital accumulation. Thus, even with $\alpha<1$ and 
production being linear in the private capital stock, the net impact on growth of higher debt is now ambiguous. In particular, the steady-state growth rate of output may now be positively related to the debt-private capital ratio. This result may be useful to understand why some empirical studies have found it difficult to detect a robust negative relationship between public debt and growth (see for instance Panizza and Presbitero (2014)) and Teles and Mussolini (2014)).

\subsection{Endogenous Risk Premium}

In practice, the interest rate on public debt often includes a premium that increases with net liabilities due to the higher (perceived) default risk by the government. ${ }^{29}$ Suppose now that there is indeed an endogenous risk of default, with a repayment probability $p_{t} \leq 1$. If the government defaults, a bond holder receives no income. Thus, the no arbitrage condition is now $p\left(1+i_{t}\right)+0 \cdot\left(1-p_{t}\right)=1+r_{t}$, or equivalently

$$
1+i_{t}=\frac{1+r_{t}}{p_{t}}
$$

where $p_{t}^{-1}$ can equivalently be defined as the risk premium.

Suppose also that the repayment probability is decreasing in the debt-private capital ratio:

$$
p_{t}=p\left(b_{t}\right)
$$

where $p^{\prime}<0$ and $p^{\prime \prime}<0$, and $\lim _{b_{t} \rightarrow 0} p_{t}=1$. Thus, the higher the debt-private capital ratio, the higher the risk premium demanded by markets for holding government debt. To fix ideas, we will assume that $p_{t}=b_{t}^{-\theta}$, where $\theta \geq 1$.

Using (39), it can be shown that (21), (24) and (25) are now replaced by

$$
\begin{gathered}
k_{t+1}^{I}=\frac{v_{I} \tau \beta}{\Lambda_{1}-(1-\beta) b_{t}^{1+\theta}}, \\
b_{t+1}=F\left(b_{t}\right)=\frac{(1-\beta) b_{t}^{1+\theta}-\Lambda_{2}}{\Lambda_{1}-(1-\beta) b_{t}^{1+\theta}}, \\
1+\gamma_{t+1}=\left(v_{I} \tau \beta\right)^{\alpha}\left[\Lambda_{1}-(1-\beta) b_{t}^{1+\theta}\right]^{1-\alpha} .
\end{gathered}
$$

\footnotetext{
${ }^{29}$ See Bi (2012) and the references therein for empirical evidence.
} 
As before, the system is recursive in $b_{t}$, and equation (41) can be solved for a given value of $\theta$. Now, consider the golden rule, for which $\Lambda_{2}<0$, and assume that the necessary condition $\Lambda_{1}>0$ for $\tilde{b}>0$ holds. The following result can then be established:

Proposition 4. Under the golden rule, the higher the sensitivity of the risk premium to the debt-private capital ratio, the more likely it is that multiple equilibria will emerge if the steady-state value of that ratio is less than unity, and the more likely that no equilibrium will exist if that ratio is higher than unity.

In order to see this, note first that the transition curve $F\left(b_{t}\right)$ is again an increasing, convex function of $b_{t}$, just like in Figure 1. Equilibrium occurs when $F()$ intersects the 45-degree line. For $\tilde{b}<1$, an increase in $\theta$ reduces $(1-\beta) \tilde{b}^{1+\theta}$, which in turn reduces $F(\tilde{b})$ and shifts the transition curve down, therefore making the possibility of multiple equilibria more likely. In contrast, for $\tilde{b}>1$ (the case of highly-indebted countries), there may be no equilibria, as a higher $\theta$ shifts the transition curve upward.

It can be observed that, in the particular case where $\theta=1$, equation (41) yields a cubic equation in $\tilde{b}$ :

$$
(1-\beta) \tilde{b}^{3}+(1-\beta) \tilde{b}^{2}-\Lambda_{1} \tilde{b}-\Lambda_{2}=0
$$

With $\Lambda_{1}>0$ and $\Lambda_{2}<0$, this equation has at most two admissible (that is, positive) solutions, as in the basic framework. ${ }^{30}$ However, the threshold value of the investment share cannot be derived analytically. From (42), it can also be seen that, regardless of the value of $\theta$, the negative relationship between $\tilde{b}$ and the growth rate continues to hold..$^{31}$

The thrust of this analysis therefore is that when markets demand a premium that responds endogenously to a country's debt level (or, in practice, perceptions about future debt levels), the possibility for that country to be stuck in a high-debt, lowgrowth equilibrium becomes more likely. From the perspective of a country like Greece

\footnotetext{
${ }^{30}$ This, again, is a direct implication of Descartes' rule of signs.

${ }^{31}$ It could be assumed alternatively that the risk premium is a function of the debt-public capital ratio (an indicator of the government's net worth) or the debt-output ratio (a common market indicator in practice). It can be verified that in either case the dynamic system is no longer recursive. For instance, with $p_{t}=\left(B_{t} / K_{t}^{I}\right)^{-\theta}$, where $\theta \geq 1$, the transition function for $b_{t+1}$ is $\left[(1-\beta)\left(k_{t}^{I}\right)^{-\theta} b_{t}^{1+\theta}-\right.$ $\left.\Lambda_{2}\right] /\left[\Lambda_{1}-(1-\beta)\left(k_{t}^{I}\right)^{-\theta} b_{t}^{1+\theta}\right]$, which depends on both $b_{t}$ and $k_{t}^{I}$. A similar equation holds for $k_{t+1}^{I}$. The properties of this system must be studied numerically.
} 
today, where (at the time of this writing) spreads on the country's sovereign debt have risen sharply due to concerns about debt sustainability, market discipline can actually complicate macroeconomic management.

\subsection{Endogenous Primary Surplus Rule}

In the foregoing discussion, the primary surplus rule that was considered assumed simply that the shares of spending sum up to a value lower than unity. Suppose instead that the rule involves a positive (and linear, for simplicity) relationship between the primary surplus and the debt ratio:

$$
1-\left(v_{I}+v_{U}\right)=\varsigma b_{t},
$$

where $\varsigma>0$. This relationship, of course, holds only for $v_{I}+v_{U}<1$. Using this specification, it can readily be established that the following dynamic system obtains:

$$
b_{t+1}=\frac{\Theta_{2} b_{t}}{\Theta_{1}-\Theta_{2} b_{t}}, \quad k_{t+1}^{I}=\frac{v_{I} \tau \beta}{\Theta_{1}-\Theta_{2} b_{t}},
$$

where $\Theta_{1}=\sigma\left[(1-\tau)+v_{U} \tau \chi\right] \beta>0$ and $\Theta_{2}=(1-\beta)-\varsigma \tau \beta \lessgtr 0$. As before, the system is recursive. The steady-state solution yields

$$
\tilde{b}=\frac{\Theta_{1}}{\Theta_{2}}-1, \quad \tilde{k}^{I}=\frac{v_{I} \tau \beta}{\Theta_{2}} .
$$

For these solutions to be admissible, the coefficient $\varsigma$ must be small enough to ensure that $0<\Theta_{2} \leq \Theta_{1}$. Once again there are no multiple equilibria. However, the key difference with the exogenous primary surplus rule is that now the trivial equilibrium $\tilde{b}=0$ is admissible; if the economy starts from a position with no debt $\left(b_{0}=0\right)$, it will stay there. Any other equilibrium point with positive debt is feasible but also unstable. ${ }^{32}$

\subsection{Generalized Golden Rule}

Consider now a flexible golden rule that involves financing a fraction $\omega \in(0,1)$ of public investment, and a fraction $\zeta \in(0,1)$ of interest payments, through bond financing. The

\footnotetext{
${ }^{32}$ As for the risk premium case considered earlier, the primary surplus rule in (43) could be specified in terms of the debt-output ratio or the debt-public capital ratio. In either case the system would no longer be recursive, but a single equilibrium would emerge once again for a wide range of plausible parameter values. These results are available upon request.
} 
government flow budget constraint and the debt accumulation equation take now the form

$$
\begin{gathered}
G_{t}^{U}+(1-\omega) G_{t}^{I}+(1-\zeta)\left(1+i_{t}\right) B_{t}=\tau w_{t}, \\
B_{t+1}=\zeta\left(1+i_{t}\right) B_{t}+\omega G_{t}^{I} .
\end{gathered}
$$

A fiscal policy rule therefore involves setting two additional parameters, $\omega$ and $\zeta$.

To ensure that (44) holds, one of the terms on the left-hand side must now be determined endogenously. We assume that it is $G_{t}^{U}$, or more precisely the share of unproductive spending. Using (6), (8) (10), and (15) yields

$$
v_{U, t}=1-(1-\omega) v_{I}-(\tau \beta)^{-1}(1-\zeta)(1-\beta) b_{t}
$$

which implies a negative relationship between the debt-private capital ratio and the share of spending on unproductive services. There is therefore a negative feedback effect of debt on government outlays. ${ }^{33}$ Because transfers to households are a fraction of unproductive spending, individual savings are given again by (14), but with $v_{U, t}$ defined as in (46). Thus, through its adverse impact on private savings, public debt accumulation has a direct crowding-out effect on private capital formation. ${ }^{34}$ If $v_{U, t}<$ 0 , the transfer is actually a tax on households.

Using the same solution procedure as before, it can be shown that

$$
k_{t+1}^{I}=\frac{v_{I} \tau \beta}{\Lambda_{5}-\Lambda_{6} b_{t}},
$$

where

$$
\begin{gathered}
\Lambda_{3}=1-(1-\omega) v_{I}>0, \\
\Lambda_{4}=(\tau \beta)^{-1}(1-\zeta)(1-\beta)>0, \\
\Lambda_{5}=\left\{\sigma\left[(1-\tau)+\Lambda_{3} \tau \chi\right]-\omega v_{I} \tau\right\} \beta,
\end{gathered}
$$

\footnotetext{
${ }^{33}$ This rule is similar in spirit to the one considered by Greiner (2007) for instance, where the ratio of the primary surplus to gross domestic income is a positive, linear function of the debt-to-income ratio. This ensures that public debt is sustainable. The reasoning behind this argument is that if a government raises the primary surplus as public debt increases, it takes corrective actions that will eventually stabilize the debt ratio. However, in Greiner's analysis, it is public investment that is determined residually.

${ }^{34}$ Note that this feedback effect on private savings is related to the fact that we assumed that transfers to households are a fixed fraction of unproductive spending. If $x_{t}$ instead had been modeled directly as a fraction of revenues, debt would have no direct effect on private savings.
} 


$$
\Lambda_{6}=\Lambda_{4} \tau \chi+\zeta(1-\beta)>0
$$

The golden rule is no longer defined as $v_{U}=1$, as long as $\zeta$ or $\omega$ is less than unity (see (46)); it now also depends on the specified values of these two parameters. ${ }^{35}$ It is easy to show that, under that rule,

$$
b_{t+1}=\frac{\zeta(1-\beta) b_{t}+\omega v_{I} \tau \beta}{\Lambda_{5}-\Lambda_{6} b_{t}}
$$

The basic framework of course corresponds to $\zeta=\omega=1$, whereas the conventional (interest exclusive) definition of the golden rule corresponds to $\zeta=0$ and $\omega=1$. The important point, however, is that with $\zeta$ and $\omega$ positive and less than unity, the shape of the transition curve is not affected; it retains a convex shape. Thus, the qualitative predictions of our benchmark model remain the same. ${ }^{36}$

The equilibrium is now the solution to the quadratic equation

$$
\Lambda_{6} \tilde{b}^{2}-\left[\Lambda_{5}-\zeta(1-\beta)\right] \tilde{b}-\omega v_{I} \tau \beta=0
$$

As before, the nature of the equilibria depends on the sign of $\Lambda_{5}-\zeta(1-\beta)$. With $\Lambda_{5}-\zeta(1-\beta)<0$, there are no positive solutions to $(47)$. With $\Lambda_{5}-\zeta(1-\beta)>0$, equation (47) can yield zero, one, or two positive solutions for $\tilde{b}$. The condition for $\Lambda_{5}-\zeta(1-\beta)>0$ is now

$$
v_{I}<\left.v_{I}^{C}\right|_{G G R} ^{1}=[\omega \tau+\sigma(1-\omega) \tau \chi]^{-1}\left\{\sigma[(1-\tau)+\tau \chi]-\frac{\zeta(1-\beta)}{\beta}\right\} .
$$

Again, $v_{I}<\left.v_{I}^{C}\right|_{G G R} ^{1}$ is a necessary condition for (47) to have an admissible solution, but it is not sufficient. In order to rule out the possibility of negative values for $\tilde{b}$, a second condition is needed, which can be expressed as $\left[\Lambda_{5}-\zeta(1-\beta)\right]^{2}-4 \Lambda_{6} \omega v_{I} \tau \beta>0$ or, equivalently, $\Lambda_{5}-\zeta(1-\beta)>2 \sqrt{\Lambda_{6} \omega v_{I} \tau \beta}$. Just as in the benchmark model, an analytical solution cannot be provided.

To illustrate the implications of having both $\zeta$ and $\omega$ less than unity we report some numerical results in Figures 5 and 6 , for the values defined earlier for $\beta, \tau, \sigma$, and $\chi\left(0.7,0.36,0.56\right.$, and 0.52 , respectively). The critical values for $v_{I}$ in the figures

\footnotetext{
${ }^{35}$ This implies also that Definition 3 should be adjusted accordingly.

${ }^{36} \mathrm{~A}$ primary balance rule for instance is now defined as $(1-\omega) v_{I}+v_{U}=1$; for (46) to hold continuously, $\zeta$ must be equal to unity, as before.
} 
yield a single equilibrium for the system, as well as being the threshold values for the existence of equilibrium. Above these critical values, there is no equilibrium whereas below these values, there are multiple equilibria. Figure 5 displays the critical values for $v_{I}$ on the vertical axis, which are by definition between zero and one, where $\chi=0.52$ (as calibrated earlier), $\zeta$ and $\omega$ are shown on the $x$-axis and $y$-axis, respectively, and they vary between 0.1 and 0.5 . For the parameters given above, there is no positive value of $v_{I}$ that yields an equilibrium beyond the values of 0.5 for $\zeta$ and $\omega$, therefore these cases are omitted. The figures clearly show that as $\zeta$ and $\omega$ increase, which means less (more) of interest payments or infrastructure spending are being financed by tax revenues (borrowing), the government can spend less (more) on infrastructure as a fraction of tax revenues, and hence the critical value for $v_{I}$ falls. Moreover, the critical values for $v_{I}$ are more sensitive to changes in $\zeta$ than $\omega$, as can be seen from the figure. At really low values of $\zeta$ and $\omega$ (when a very large fraction of interest payments and infrastructure spending are financed by tax revenues), the condition is not binding, as the critical value for $v_{I}$ exceeds one in that case - and is therefore not feasible.

In Figure $6, \zeta$ is set at 0.25 (a reasonable value for the share of interest payments financed through through bond issuance), and $\omega$ and $\chi$ are varied again between 0.1 and 0.5 in order to analyze the effect of the share of transfers in unproductive spending on the critical value of $v_{I}$. As before, $\omega$ is shown on the $y$-axis whereas $\chi$ is on the $x$-axis this time. The figure shows that an increase in the share of transfers in unproductive government spending reduces the critical value of $v_{I}$ as well. However, this effect is much smaller than an increase in $\zeta$, as can be seen by comparing the two figures.

Note also that, again, the earlier result of a negative steady-state relationship between the debt ratio and the growth rate continues to hold, regardless of the values of $\omega, \chi$ and $\zeta$.

\subsection{Network Externalities}

Suppose now that public capital is subject to network externalities, which induce nonlinearities in its productivity. In general, the productivity gain of additional infrastructure investment is a combination of two distinct effects. On the one hand, a new network user unequivocally increases the value of the network: she gains from 
being connected to the other network members, while the latter have a (small) gain from being connected to her. On the other, as documented in the diffusion literature, the user base of a network increases in a nonlinear (logistic) fashion in investment (see Rogers (2003)). Here we focus on the case where the combination of these effects generates a convex form of the network externalities.

Specifically, we assume that until the network is built, public capital has a relatively low (and constant) marginal productivity. Once the basic parts of a network are established, and a critical mass has been reached (say, $k_{m}^{I}$ ), strong gains are associated with small additional increases in infrastructure investment. Beyond that (for $k_{t}^{I}>$ $\left.k_{m}^{I}\right)$, the extra marginal productivity gains induced by additional investments tend to slow down or to disappear. This can be captured by assuming that the degree of efficiency of infrastructure is nonlinearly related to the (congestion-adjusted) stock of public capital itself. ${ }^{37}$

The aggregate production function therefore takes the form, instead of (8),

$$
Y_{t}=\left[f\left(k_{t}^{I}\right) k_{t}^{I}\right]^{\alpha} K_{t}^{P}
$$

where $f(0)=1, f^{\prime}>0$, and $f^{\prime \prime}>0$ for $k_{t}^{I} \leq k_{m}^{I}$, and $f^{\prime \prime}<0$ for $k_{t}^{I}>k_{m}^{I}$. Thus, network effects take a convex form. To fix ideas, we set $f\left(k_{t}^{I}\right)=\left(k_{t}^{I}\right)^{\varepsilon}$, where $\varepsilon>1$ over the range $k_{t}^{I} \in\left(0, k_{m}^{I}\right)$ and $\varepsilon=0$ for $k_{t}^{I}>k_{m}^{I}$.

It is straightforward to show that the steady-state solutions (26) and (27) for $b_{t}$ and $k_{t}^{I}$ remain the same (which implies, in particular, that neither $\alpha$ nor $\varepsilon$ affects the threshold values of $v_{I}$ in the basic framework), whereas (28) is replaced by

$$
1+\gamma=\left\{\begin{array}{cc}
\left(v_{I} \tau \beta\right)^{\alpha(1+\varepsilon)}\left[\Lambda_{1}-(1-\beta) \tilde{b}\right]^{1-\alpha(1+\varepsilon)} & \tilde{k}^{I} \in\left(0, k_{m}^{I}\right) \\
\left(v_{I} \tau \beta\right)^{\alpha}\left[\Lambda_{1}-(1-\beta) \tilde{b}\right]^{1-\alpha} & \tilde{k}^{I}>k_{m}^{I}
\end{array} .\right.
$$

Based on this solution, and the results of the previous section, the following proposition can be established.

Proposition 5. If $\tilde{k}^{I} \in\left(0, k_{m}^{I}\right)$, and network externalities are sufficiently strong $\left(\varepsilon>\alpha^{-1}-1\right)$, a low (high) debt equilibrium under the golden rule is associated with a low (high) steady-state growth rate of output.

\footnotetext{
${ }^{37}$ See for instance Agénor (2010). Evidence of threshold effects in the relationship between output growth and infrastructure is provided by Röller and Waverman (2001), Égert et al. (2009), Czernich et al. (2011), Roberts and Deichmann (2011), Candelon et al. (2013), and Agénor and Neanidis (2015).
} 
Based on the long-run value estimated by Bom and Ligthart (2014, Table 4), using meta-regression analysis for core public capital at the national level, $\alpha=0.17$; the restriction on $\varepsilon$ is thus $\varepsilon>4$.88. However, based on the central simultaneous-equation estimate of Agénor and Neanidis (2015), $\alpha=0.26$ and the condition is $\varepsilon>2.84$; at the higher end of their estimates, $\alpha=0.38$, the condition becomes $\varepsilon>1.63$. And based on the estimates of the elasticity of output to infrastructure reported in European Commission (2014, Appendix 3), which vary between 0.06 to 0.84, at the upper range of these values the condition is only $\varepsilon>0.19$.

Thus, the steady-state growth rate of output may now be positively related to the debt-private capital ratio. Intuitively, this result holds because with network externalities, and with the marginal product of private capital depending positively on the available stock of public capital, the crowding-in effect is stronger - at least up to a certain level of the public-private capital ratio. In addition, the effect of a shift in the share of spending on investment on growth is now magnified. As with partial depreciation, this result may be useful to explain the ambiguous empirical evidence on the link between public debt and growth.

However, with $\varepsilon$ high enough, the high-debt, high-growth equilibrium (Point $B^{\prime}$ in Figure 1) remains unstable; unless the economy starts there, it cannot be reached over time. Suppose instead that the initial equilibrium is at Point $B$, which (again, with $\varepsilon$ high enough) is now a low-debt, low-growth equilibrium. Because, as shown earlier, this equilibrium exists only when $v_{I}<\left.v_{I}^{C}\right|_{v_{U}=1} ^{2}$, an increase in the share of investment to exactly $\left.v_{I}^{C}\right|_{v_{U}=1} ^{2}$ will shift the economy from Point $B$ to Point $A$, an equilibrium characterized by higher growth and a higher debt-private capital ratio.

An obvious question, of course, is whether Point $B$ is preferable to Point $A$ (or any point located to the Northeast of $B$, corresponding to a higher $v_{I}$ ), from a welfare point of view. Intuitively, the output growth effect, which is positive, is likely to be welfare-improving. At the same time, however, higher debt means a higher burden on future generations, and this may be welfare reducing. In general, therefore, whether an equilibrium with higher debt and higher growth is preferable to an equilibrium with low debt and low growth (such as Point $B$ ) from a welfare standpoint is likely to be ambiguous. This result is formally established in Appendix 2, where the welfare 
analysis is restricted to the balanced growth path. However, as also shown in Appendix 2 , the stronger the network externality, the more likely it is that the net welfare effect will be positive, reflecting the strength of the growth effect. In addition, the condition established in Proposition 5 is sufficient, although not necessary, for the welfare effect to be unambiguously positive. ${ }^{38}$

These simple results have important practical implications for industrial countries and for those developing countries where market-based bond financing of public deficits is a viable option. For the latter group of countries, where stocks of infrastructure are relatively low to begin with, there is strong evidence to suggest that network effects associated with additional investment are likely to be strong across a broad range of infrastructure assets. For industrial countries, even though these externalities in "basic" infrastructure such as roads and telecommunications may have long been exhausted, there are certain types of infrastructure for which they are likely to remain powerful - in particular, high-speed rail, air-traffic control systems, and high-speed broadband. In the case of broadband, studies by the European Union have shown that the replacement of aging copper networks with next-generation optic fiber networks could have a substantial impact on growth. ${ }^{39}$

Even though sustainability considerations may impose limits on all types of spending, our results illustrate the importance of preserving, even in a context of fiscal retrenchment, the allocation of resources to specific types of public investment - those with potentially strong externalities with respect to private production. In fact, externalities associated with infrastructure may exist not only with respect to its impact on the production of goods, but also (as is the case for broadband, for instance) for the production of human capital and the capacity to innovate - both of which likely to

\footnotetext{
${ }^{38}$ Adding a utility benefit to public capital (improved access to faster transportation may enhance leisure, for instance) implies that the net welfare gain would be more likely to be positive. Doing so would not affect the derivations provided earlier, as long as it is introduced additively in the household utility function. Conversely, however, if unproductive spending $G_{t}^{U}$ were to affect utility, under a generalized golden rule an increase in $v_{I}$ would lower $v_{U}$ (as implied by (46)), and the change in welfare would be ambiguous.

${ }^{39}$ In principle, to account for the possibility that network externalities may exist only for a certain category of infrastructure assets, we should introduce two types of infrastructure in the model. However, this would only complicate the analysis without adding any insight.
} 
promote growth. ${ }^{40}$

\section{Concluding Remarks}

The purpose of this paper was to analyze the dynamics of public debt in a simple two-period overlapping generations model of endogenous growth with productive public goods. Considering first a basic framework, alternative fiscal rules were defined, including a golden rule whereby investment in infrastructure, and interest payments on public debt, were financed by issuing bonds. Conditions under which a single equilibrium and multiple equilibria may emerge were characterized. It was also shown that the steady-state relationship between output growth and the debt-private capital ratio is unambiguously negative under the golden rule, implying that, with multiple equilibria, the low- (high-) debt equilibrium is associated with a higher (lower) growth rate. Intuitively, an increase in the share of public spending on investment has two opposite effects on fiscal sustainability. On the one hand, it raises the public capital stock, improves productivity of private inputs, and raises the accumulation of private capital, thereby promoting the rate of economic growth. On the other, it results in higher interest rates and leads to more public debt accumulation. This has a negative impact on fiscal sustainability due to the crowding-out of private capital, and this hampers growth. However, even though the growth rate and the public debt-private capital ratio are inversely related in the steady state, it was shown that an increase in the share of investment in infrastructure has an ambiguous effect on long-run growth: on the one hand, it raises the debt-private capital ratio, which tends to lower growth; on the other, it raises the public-private capital ratio, both directly and indirectly. If the elasticity of output with respect to public capital is sufficiently high, the steadystate growth rate of output will increase. This result was established because, unlike previous studies, a proper distinction was made between the elasticities of output with respect to labor and public capital.

The analysis was then extended to consider the case of partial depreciation, an endogenous risk premium, an endogenous primary surplus rule, a generalized golden

\footnotetext{
${ }^{40}$ See Agénor (2012) and Agénor and Neanidis (2015) for a discussion and empirical evidence.
} 
rule, and network externalities. With an endogenous risk premium, the higher the sensitivity of that premium to the debt-private capital ratio, the more likely it is that multiple equilibria will emerge if the steady-state value of that ratio is less than unity; in contrast, if the debt-private capital ratio is too high, it is more likely that there may be no equilibria. With the generalized golden rule, the crowding-out effect on private capital formation associated with public debt accumulation is magnified, as a result of a direct effect on transfers and household savings. The higher the proportion of interest payments financed by tax revenues, the higher is the (sustainable) share of these revenues that the government can spend on infrastructure - despite the fact that this increase lowers the share of other spending, including transfers, and thus private savings and investment. With network externalities, the qualitative features of the dynamics of the debt-private capital ratio do not change, but a steady-state characterized by high growth and high public debt can now emerge if network effects are sufficiently strong. This is in contrast to the inverse steady-state relationship between output growth and the debt-private capital ratio obtained in the basic framework and the rest of the literature. A large enough increase in the share of output allocated to public investment may shift the economy from a low-growth, low-debt equilibrium to an equilibrium characterized by both higher debt and higher growth. This shift may be welfare-enhancing as well, particularly so if in addition to its productivity effects public capital generates some utility benefits.

Despite the simplicity of the model, these results have important implications for the current debate on fiscal consolidation and growth, especially in industrial countries. Even though network externalities may have long been exhausted for many types of "basic" infrastructure assets, they are likely to remain strong for some specific types, such as high speed rail and broadband. And if indeed these effects are strong, the analysis in this paper illustrates the importance of preserving, even in a context of fiscal consolidation, a sufficient level of public investment. A well-designed fiscal adjustment program can both promote growth and ensure fiscal sustainability in the long run.

The analysis can be extended in several directions. In particular, alternative fiscal rules can be studied, along the lines of Turnovsky (1997), Bohn (1998), Buiter (2004), Annichiarico and Giammarioli (2008), Futagami et al. (2008), Fernández-Huertas and 
Vidal (2010), and Michel et al. (2010), who consider endogenous responses of both spending (especially unproductive outlays) and tax rates to deviations in the debtoutput ratio. A broader focus on different ways of financing productive government spending, would indeed help to shed light on some of the policy options that governments often face in practice. ${ }^{41}$ In the present case, if the tax rate increases sufficiently rapidly with the debt-output ratio (or deviations in that ratio from its steady-state value), as in a "spend and tax" approach, the transition curve $F\left(b_{t}\right)$ in (24) may turn concave ensuring therefore a stable, single long-run equilibrium. Such feedback rules may be part of balanced-budget rules, which are the most common in practice. Intuitively, it is likely that with feedback rules of this type stability will depend critically on what the target level of the debt-output ratio is. However, the possibility of multiple equilibria (some of them unstable) will also remain.

\footnotetext{
${ }^{41}$ In this context, political economy considerations focusing on conflicts between young and old on ways to finance productive spending may be important. See Song et al. (2012) and Lancia and Russo (2013). In the latter paper for instance, the middle aged support productive investment (in education) today, even though they do not benefit from it directly, because they want to ensure that the tax base is sufficiently large next period (when they are old) to finance transfers.
} 


\section{Appendix 1}

This Appendix discusses in more detail the case of partial depreciation rates for public and private capital and considers briefly the case of a nonseparable utility function. To simplify matters, these extensions are considered separately.

Consider first partial depreciation of private and public capital. Using (33), equation (17) is thus replaced by

$$
K_{t+1}^{P}=\Lambda_{1} Y_{t}-\left(1+i_{t}\right) B_{t}+\left(1-\delta^{P}\right) K_{t}^{P},
$$

where $\Lambda_{1}$ is defined in the text. Using again (33), equation (19) becomes

$$
\frac{K_{t+1}^{P}}{K_{t}^{P}}=\Lambda_{1}\left(k_{t}^{I}\right)^{\alpha}-(1-\beta)\left(k_{t}^{I}\right)^{\alpha} b_{t}+1-\delta^{P} .
$$

Similarly, from (8), (10), and (32), equation (20) becomes

$$
\frac{K_{t+1}^{I}}{K_{t}^{I}}=v_{I} \tau \beta\left(\frac{Y_{t}}{K_{t}^{I}}\right)+1-\delta^{G}=v_{I} \tau \beta\left(k_{t}^{I}\right)^{\alpha-1}+1-\delta^{G} .
$$

Dividing (A2) by (A1) gives

$$
k_{t+1}^{I}=\frac{v_{I} \tau \beta+\left(1-\delta^{G}\right)\left(k_{t}^{I}\right)^{1-\alpha}}{\Lambda_{1}-(1-\beta) b_{t}+\left(1-\delta^{P}\right)\left(k_{t}^{I}\right)^{-\alpha}} .
$$

The equation that determines the dynamics of public debt, (22), remains the same:

$$
\frac{B_{t+1}}{B_{t}}=\left[(1-\beta)-\Lambda_{2} b_{t}^{-1}\right]\left(k_{t}^{I}\right)^{\alpha}
$$

where $\Lambda_{2}$ is defined in the text. Dividing (A4) by (A1) gives now

$$
b_{t+1}=\frac{(1-\beta) b_{t}-\Lambda_{2}}{\Lambda_{1}-(1-\beta) b_{t}+\left(1-\delta^{P}\right)\left(k_{t}^{I}\right)^{-\alpha}} .
$$

Equations (A3) and (A5) represent a highly nonlinear system, whose steady-state solution is given by

$$
\begin{gathered}
\tilde{k}^{I}-\frac{v_{I} \tau \beta+\left(1-\delta^{G}\right)\left(\tilde{k}^{I}\right)^{1-\alpha}}{\Lambda}=0, \\
\tilde{b}-\frac{(1-\beta) \tilde{b}-\Lambda_{2}}{\Lambda}=0
\end{gathered}
$$

where

$$
\Lambda=\Lambda_{1}-(1-\beta) \tilde{b}+\left(1-\delta^{P}\right)\left(\tilde{k}^{I}\right)^{-\alpha} .
$$


In general this system cannot be solved analytically. Equation (A6) can be rearranged as

$$
\tilde{b}=\frac{\Lambda_{1}}{(1-\beta)}-\frac{v_{I} \tau \beta}{(1-\beta) \tilde{k}^{I}}+\frac{\delta^{G}-\delta^{P}}{(1-\beta)\left(\tilde{k}^{I}\right)^{\alpha}},
$$

with $\lim _{\tilde{k}^{I} \rightarrow \infty} \tilde{b}=\Lambda_{1} /(1-\beta)$. Again, by applying the implicit function theorem, it can be established that (A8) gives an increasing but nonmonotonic relationship between $\tilde{k}^{I}$ and $\tilde{b}$, depending on the sign of $\delta^{G}-\delta^{P}$. Thus, the steady-state conditions (A7) and (A8) may now be highly nonlinear in the $\tilde{k}^{I}-\tilde{b}$ space, implying again that depending not only on how low $\delta^{G}$ and $\delta^{P}$ are (compared to the benchmark case of $\delta^{G}=\delta^{P}=1$ ), but also on the sign of $\delta^{G}-\delta^{P}$, more than two equilibria may emerge. To characterize these equilibria a numerical analysis is needed.

With $\delta^{P}=1$ and $\delta^{G}<1$, the steady-state solution of (36) is given by

$$
G\left(\tilde{b}, \tilde{k}^{I}\right)=\tilde{k}^{I}\left[\Lambda_{1}-(1-\beta) \tilde{b}\right]-\left(1-\delta^{G}\right)\left(\tilde{k}^{I}\right)^{1-\alpha}-v_{I} \tau \beta=0
$$

from which it can be established that $G_{\tilde{b}}<0$ and $G_{\tilde{k}^{I}} \gtrless 0$, depending, in particular, on the values of $\alpha$ and $\delta^{G}$. Thus, assuming that $G_{\tilde{k}^{I}} \neq 0$, the implicit function theorem implies that now $d \tilde{k}^{I} / d \tilde{b} \gtrless 0$.

Suppose now that the period utility function, instead of (1), takes a constant relative risk aversion (CRRA) form, with the household therefore solving the problem

$$
\max _{c_{t}^{t}, c_{t+1}^{t}} U_{t}=\frac{\left(c_{t}^{t}\right)^{1-\varsigma^{-1}}}{1-\varsigma^{-1}}+\Omega \frac{\left(c_{t+1}^{t}\right)^{1-\varsigma^{-1}}}{1-\varsigma^{-1}},
$$

where $\Omega=1 /(1+\rho)$ is the discount factor and $\varsigma$ the elasticity of intertemporal substitution. The budget constraint remains the same as (5). Solving the household's optimization problem, it can be shown in standard fashion that the savings rate is no longer constant; it is given by $\sigma_{t}=\sigma\left(r_{t+1}\right)$, from which it can be established that $d \sigma_{t} / d r_{t+1}<0$ if $\varsigma<1$, whereas $d \sigma_{t} / d r_{t+1}>0$ if $\varsigma>1$. Thus, the effect of the interest rate on savings is generally ambiguous, which reflects the fact that the substitution and income effects on consumption of a change in the interest rate operate in opposite directions.

Explicit analytical solutions cannot be established in this case but intuitively the implications of an endogenous savings rate are fairly clear. Let us consider the conventional case where an increase in the interest rate therefore raises savings and, given the definition of $\Lambda_{1}$ in (18), private capital accumulation. From (6) and (8), the interest rate is a linear function of the public-private capital ratio. In turn, from (21) and (24), both $b_{t+1}$ and $k_{t+1}^{I}$ depend on $k_{t}^{I}$; the dynamics of the public debt-private capital ratio and public-private capital ratio are now interdependent. In particular, the steady-state equations (26) and (27) are replaced by

$$
(1-\beta) \tilde{b}^{2}-\left[\Lambda_{1}\left(\tilde{k}^{I}\right)-(1-\beta)\right] \tilde{b}-\Lambda_{2}=0,
$$




$$
\tilde{k}^{I}\left[\Lambda_{1}\left(\tilde{k}^{I}\right)-(1-\beta) \tilde{b}\right]-v_{I} \tau \beta=0,
$$

where now $d \Lambda_{1} / \tilde{k}^{I}>0$. These equations must be solved numerically to determine whether multiple equilibria can emerge. Even though it can be established (by applying the implicit function theorem) that the second equation implies that $\tilde{k}^{I}=\Phi(\tilde{b})$, with $\Phi^{\prime}>0$, both curves may now be highly nonlinear in the $\tilde{k}^{I}-\tilde{b}$ space, implying that if the sensitivity of $\sigma$ with respect to the interest rate is high, more than two equilibria may emerge. Conversely, as can be inferred from (18), the endogeneity of $\sigma$ has limited impact on the analysis if $(1-\tau)+v_{U} \tau \chi$ is close to zero; however, this implies $\tau(1-$ $\left.v_{U} \chi\right)=1$, a condition that cannot be fulfilled given the restrictions on $\tau, v_{U}$ and $\chi$ being all less than unity. 


\section{Appendix 2}

This Appendix examines the effect of an increase in the infrastructure spending share on welfare, along the balanced growth path. In standard fashion, assume that the government's welfare function is a discounted sum of the utility of the representative individual of the present and all future generations, $W_{t}=\sum_{t=0}^{\infty} \xi^{t} U_{t}$, where $\xi \in(0,1)$ is a constant discount factor which reflects social time preferences and may differ from each individual's subjective discount factor.

From (1), the utility function can be written as

$$
U_{t}=\ln c_{t}^{t}+\Gamma_{1} \ln c_{t+1}^{t},
$$

where $\Gamma_{1}=1 /(1+\rho)$. From $(2),(6)$, and (14), $c_{t}^{t}$ can be written as

$$
c_{t}^{t}=\Gamma_{2} Y_{t},
$$

where

$$
\Gamma_{2}=(1-\sigma)\left[(1-\tau)+v_{U} \tau \chi\right] \beta .
$$

Similarly, from (3), (6), (8), and (14) yields

$$
c_{t+1}^{t}=\Gamma_{3}\left(k_{t+1}^{I}\right)^{\alpha} Y_{t},
$$

where

$$
\Gamma_{3}=\sigma(1-\beta)\left[(1-\tau)+v_{U} \tau \chi\right] \beta .
$$

Substituting (B2) and (B3) in (B1) implies that the representative individual's lifetime utility is

$$
U_{t}=\Gamma_{4}+\left(1+\Gamma_{1}\right) \ln Y_{t}+\alpha \Gamma_{1} \ln k_{t+1}^{I},
$$

where

$$
\Gamma_{4}=\ln \Gamma_{2}+\Gamma_{1} \ln \Gamma_{3}
$$

Along the balanced growth path, the public-private capital stock is constant at $\tilde{k}^{I}$, as shown in the text. The above expression becomes

$$
\tilde{U}_{t}=\Gamma_{4}+\left(1+\Gamma_{1}\right) \ln \tilde{Y}_{t}+\alpha \Gamma_{1} \ln \tilde{k}^{I} .
$$

In addition, along the steady-state equilibrium path, $\tilde{Y}_{t}=Y_{0}(1+\gamma)^{t}$. Substituting this result in the above expression yields

$$
\tilde{U}_{t}=\Gamma_{5}+\left(1+\Gamma_{1}\right) t \ln (1+\gamma)+\alpha \Gamma_{1} \ln \tilde{k}^{I}
$$

where

$$
\Sigma_{5}=\Sigma_{4}+\left(1+\Sigma_{1}\right) \ln Y_{0} .
$$


This expression implies that welfare is increasing in the growth rate $1+\gamma$, given in (28), and depends on time. From (27) and (28),

$$
1+\gamma=\left(\tilde{k}^{I}\right)^{\alpha}\left[\Lambda_{1}-(1-\beta) \tilde{b}\right]
$$

Substituting this expression in (B4) yields

$$
\tilde{U}_{t}=\Sigma_{5}+\alpha\left[\left(1+\Sigma_{1}\right) t+\Sigma_{1}\right] \ln \tilde{k}^{I}+\left(1+\Sigma_{1}\right) t \ln \left[\Lambda_{1}-(1-\beta) \tilde{b}\right] .
$$

Equation $(27)$ can be rewritten as $\left[\Lambda_{1}-(1-\beta) \tilde{b}\right]=v_{I} \tau \beta\left(\tilde{k}^{I}\right)^{-1}$. Substituting this result again in (B5) yields now

$$
\tilde{U}_{t}=\Gamma_{5}+\left[(\alpha-1)\left(1+\Gamma_{1}\right) t+\alpha \Gamma_{1}\right] \ln \tilde{k}^{I}+\left(1+\Gamma_{1}\right) t \ln v_{I} \tau \beta .
$$

Consider first the case where $t \rightarrow 0$. Expression (B6) boils down to

$$
\tilde{U}_{0}=\Gamma_{5}+\alpha \Gamma_{1} \ln \tilde{k}^{I}
$$

As discussed in the text, under all the fiscal rules considered in the paper, an increase in $v_{I}$ unambiguously increases $\tilde{k}^{I}$. Thus, under the (interest-inclusive) golden rule, under which $v_{U}=1$ and $d \Gamma_{5} / d v_{I}=0$, investing more today increases welfare unambiguously if the government is concerned only with the welfare of the present generation. However, note that with the generalized golden rule, the condition $v_{U}=1$ does not hold anymore, and $d \Gamma_{5} / d v_{I}<0$. Thus, even if the government is concerned only with the welfare of the present generation, higher $v_{I}$ does not necessarily imply an increase in welfare.

Consider now the case where $t>0$. Inspection of (B6) shows that an increase in $v_{I}$ raises the last term directly. Under the (interest-inclusive) golden rule, again, $d \Gamma_{5} / d v_{I}=0$. In addition, an increase in $v_{I}$ (as noted earlier) increases $\tilde{k}^{I}$. However, whether the second term in (B6) is positive or negative depends on the sign of ( $\alpha-$ $1)\left(1+\Gamma_{1}\right) t+\alpha \Gamma_{1}$, and thus also on $t$. If $\alpha$ is sufficiently less than one, for $t$ given, this term can be negative. If it exceeds the third term, then the net effect on welfare can be negative. Conversely, if $\alpha$ is sufficiently high, the net welfare effect will be positive. Intuitively, the source of the ambiguity is due to the fact that the burden of debt is shifted across generations, which ensures that the "crowding out" effect perpetuates itself. Unless the growth (or "crowding in") effect of public capital is strong, future generations are worse off as a result.

Finally, note that if there are network externalities, the term $\alpha-1$ in (B6) would be replaced by $\alpha(1+\varepsilon)-1$. If so, the stronger the network externality, the more likely it is that the net welfare effect will be positive, reflecting the strength of the growth effect. In addition, $\alpha(1+\varepsilon)>1$ is a sufficient (although not necessary) for the welfare effect to be unambiguously positive. 


\section{References}

Agénor, Pierre-Richard, "A Theory of Infrastructure-led Development," Journal of Economic Dynamics and Control, 34 (May 2010), 932-50.

—, Public Capital, Growth and Welfare, Princeton University Press (Princeton, New Jersey: 2012).

Agénor, Pierre-Richard, and Kyriakos Neanidis, "Innovation, Public Capital, and Growth," Journal of Macroeconomics, 44 (June 2015), 252-75.

Agénor, Pierre-Richard, and Devrim Yilmaz, "The Tyranny of Rules: Fiscal Discipline, Productive Spending, and Growth in a Perfect Foresight Model," Journal of Economic Policy Reform, 14 (March 2011), 69-99.

Annichiarico, Barbara, and Nicola Giammarioli, "Fiscal Rules and Sustainability of Public Finances in an Endogenous Growth Model," unpublished, European Central Bank (April 2008).

Arai, Real, "Productive Government Expenditure and Fiscal Sustainability," FinanzArchiv, 67 (December 2011), 327-51.

Barro, Robert J., "Government Spending in a Simple Model of Endogenous Growth," Journal of Political Economy, 98 (October 1990), s103-s25.

Bi, Huikin, "Sovereign Default Risk Premia, Fiscal Limits, and Fiscal Policy," European Economic Review, 56 (April 2012), 389-410.

Bohn, Henning, "The Behavior of U.S. Public Debt and Deficits," Quarterly Journal of Economics, 113 (August 1998), 949-63.

Bom, Pedro R., and Jenny E. Ligthart, "What Have we Learned from Three Decades of Research on the Productivity of Public Capital?," Journal of Economic Surveys, 28 (December 2014), 889-916.

Brauninger, Michael, "The Budget Deficit, Public Debt, and Endogenous Growth," Journal of Public Economic Theory, 7 (December 2005), 827-40.

Buiter, Willem H., "Fiscal Sustainability," unpublished, European Bank for Reconstruction and Development (January 2004).

Candelon, Bertrand, Gilbert Colletaz, and Christophe Hurlin, "Network Effects and Infrastructure Productivity in Developing Countries," Oxford Bulletin of Economics and Statistics, 75 (December 2013), 887-913.

Chalk, Nigel A., "The Sustainability of Bond-Financed Deficits: An Overlapping Generations Approach," Journal of Monetary Economics, 45 (April 2000), 293-328.

Collignon, Stefan, "Fiscal Policy Rules and the Sustainability of Public Debt in Europe," International Economic Review, 53 (May 2012), 539-67.

Czernich, Nina, Oliver Falck, Tobias Kretschmer, and Ludger Woessmann, "Broadband Infrastructure and Economic Growth," Economic Journal, 121 (May 2011), 505-32. 
De la Croix, David, and Philippe Michel, A Theory of Economic Growth: Dynamics and Policy in Overlapping Generations, Cambridge University Press (Cambridge: 2002). Égert, Balázs, Tomasz Kozluk, and Douglas Sutherland, "Infrastructure and Growth: Empirical Evidence," Working Paper No. 26, OECD Economics Department (March 2009).

European Commission, "Infrastructure in the EU: Developments and Impact on Growth," Occasional Paper No. 203, European Economy Series (December 2014).

Fernández-Huertas, Moraga, and Jean-Pierre Vidal, "Fiscal Sustainability and Public Debt in an Endogenous Growth Model," Journal of Pension Economics and Finance, 9 (June 2010), 277-302.

Futagami, Koichi, Tatsuro Iwaisako, and Ryoji Ohdoi, "Debt Policy Rule, Productive Government Spending, and Multiple Growth Paths," Macroeconomic Dynamics, 12 (December 2008), 445-62.

Futagami, Koichi, and Akihisa Shibata, "Budget Deficits and Economic Growth," Public Finance, 53 (March 2003), 331-54.

Ghosh, Sugata, and Iannis A. Mourmouras, "Endogenous Growth, Welfare and Budgetary Regimes," Journal of Macroeconomics, 26 (December 2004), 623-35.

Ghosh, Sugata, and Charles Nolan, "The Impact of Simple Fiscal Rules in Growth Models with Public Goods and Congestion," Manchester School, 75 (September 2007), 634-51.

Greiner, Alfred, "An Endogenous Growth Model with Public Capital and Sustainable Government Debt," Japanese Economic Review, 58 (September 2007), 345-61.

_- "Economic Growth, Public Debt and Welfare: Comparing Three Budgetary Rules," German Economic Review, 12 (May 2011), 205-22.

— "Public Capital, Sustainable Debt and Endogenous Growth," Research in Economics, 66 (September 2012), 230-38.

Greiner, Alfred, and Peter Flaschel, "Public Debt and Public Investment in an Endogenous Growth Model with Real Wage Rigidities," Scottish Journal of Political Economy, 57 (February 2010), 68-84.

Greiner, Alfred, and Willi Semmler, "Endogenous Growth, Government Debt, and Budgetary Regimes," Journal of Macroeconomics, 22 (June 2000), 363-84.

Inderst, Georg, "Private Infrastructure Finance and Investment in Europe," Working Paper No. 2013/02, European Investment Bank (June 2013).

International Monetary Fund, Back To Work: How Fiscal Policy Can Help, Fiscal Monitor (Washington DC: 2014).

Lancia, Francesco, and Alessia Russo, "A Dynamic Politico-Economic Model of Intergenerational Contracts," Department of Economics Paper No. 1304, University of Vienna (2013).

Michel, Philippe, Leopold von Thadden, and Jean-Pierre Vidal, "Debt Stabilizing Fiscal Rules," Journal of Public Economic Theory, 12 (October 2010), 923-41. 
Minea, Alexandru, and Patrick Villieu, "Persistent Deficit, Growth, and Indeterminacy," Macroeconomic Dynamics, 16 (September 2012), 267-83.

Roberts, Mark, and Uwe Deichmann, "International Growth Spillovers, Geography and Infrastructure," The World Economy, 34 (September 2011), 1507-33.

Rogers, Everett M., Diffusion of Innovations, 5th ed., Free Press (New York: 2003).

Röller, Lars-Hendrik, and Leonard Waverman, "Telecommunications Infrastructure and Economic Development: A Simultaneous Approach," American Economic Review, 91 (September 2001), 909-23.

Song, Zheng, Kjetil Storesletten, Fabrizio Zilibotti, "Rotten Parents and Disciplined Children: A Politico-Economic Theory of Public Expenditure and Debt," Econometrica, 80 (November 2012), 2785-803.

Teles, Vladimir K., and Caio C. Mussolini, "Public Debt and the Limits of Fiscal Policy to Increase Economic Growth," European Economic Review, 66 (February 2014), 1-15.

Turnovsky, Stephen J., "Fiscal Policy in a Growing Economy with Public Capital," Macroeconomic Dynamics, 1 (September 1997), 615-39.

—, "The Transitional Dynamics of Fiscal Policy: Long-Run Capital Accumulation and Growth," Journal of Money, Credit, and Banking, 36 (October 2004), 883-910.

Yakita, Akira, "Sustainability of Public Debt, Public Capital Formation, and Endogenous Growth in an Overlapping Generations Setting," Journal of Public Economics, 92 (April 2008), 879-914. 
Table 1

Parameter Values

\begin{tabular}{cll}
\hline \hline Parameter & Value & \multicolumn{1}{c}{ Description } \\
\hline \hline$\sigma$ & 0.56 & Adjusted savings rate \\
$\tau$ & 0.36 & Effective tax rate (adjusted for labor share) \\
$\chi$ & 0.52 & Share of transfers in unproductive public spending \\
$v_{I}$ & 0.052 & Share of investment in total public spending \\
$\omega$ & 0 to 1 & Share of investment financed by issuing bonds \\
$\zeta$ & 0 to 1 & Share of interest payments financed by issuing bonds \\
$\beta$ & 0.7 & Labor elasticity of output \\
$\alpha$ & 0.17 & Elasticity of output to public capital, base case \\
\hline \hline
\end{tabular}


Figure 1

Dynamics of the Public Debt-Private Capital Ratio

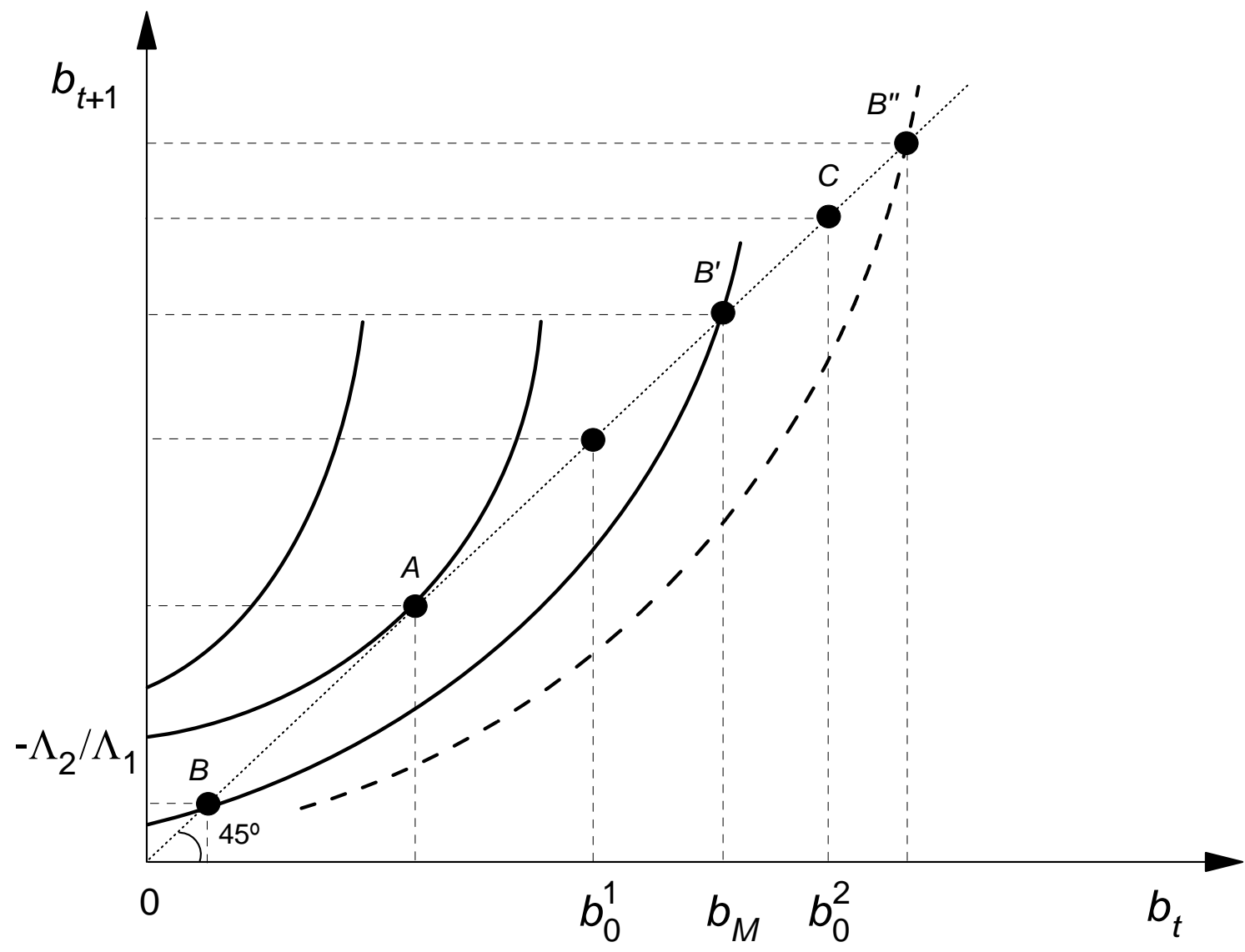


Figure 2

Equilibria and Threshold Shares of Public Investment

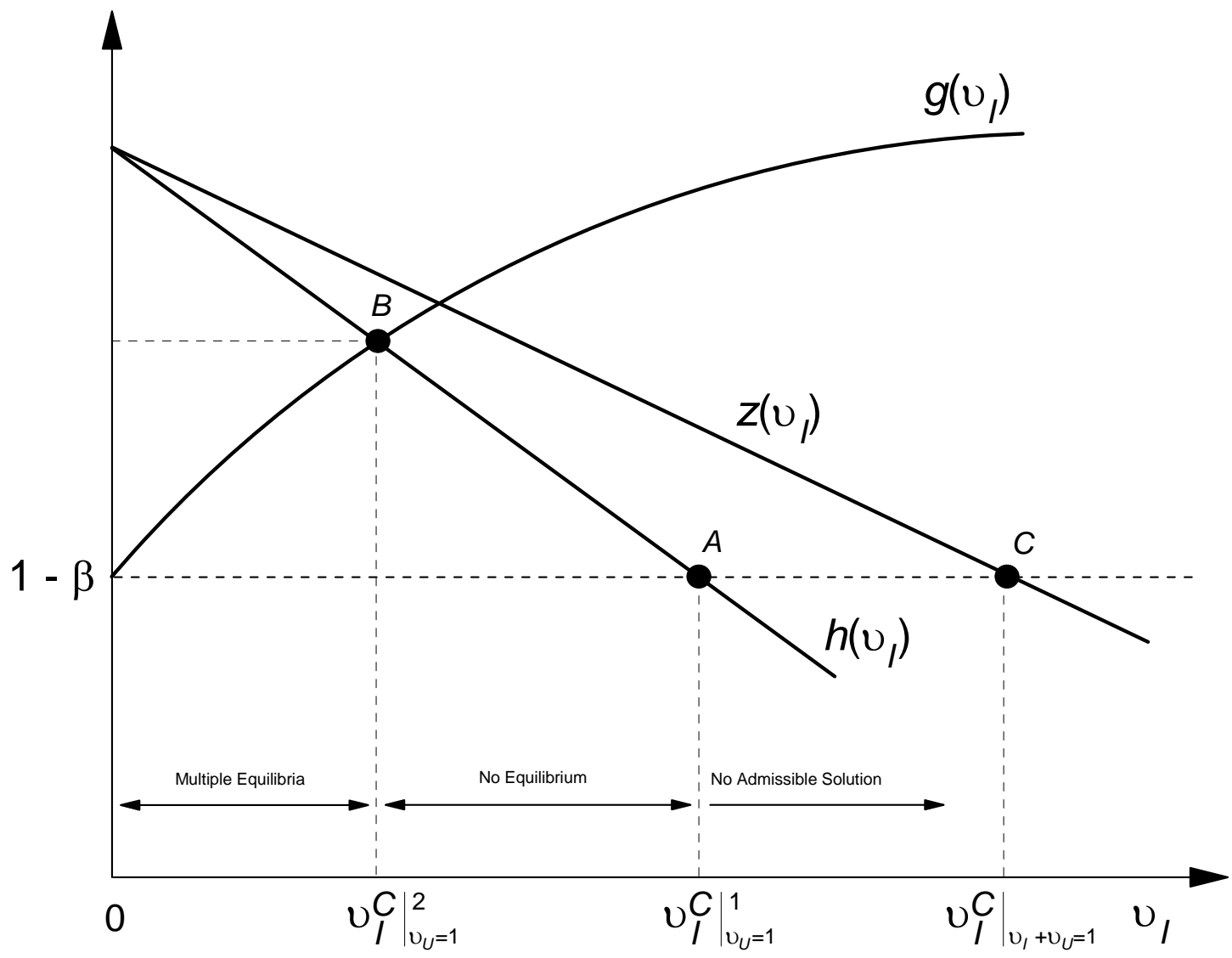


Figure 3

Golden Rule: Multiple Steady-State Equilibria

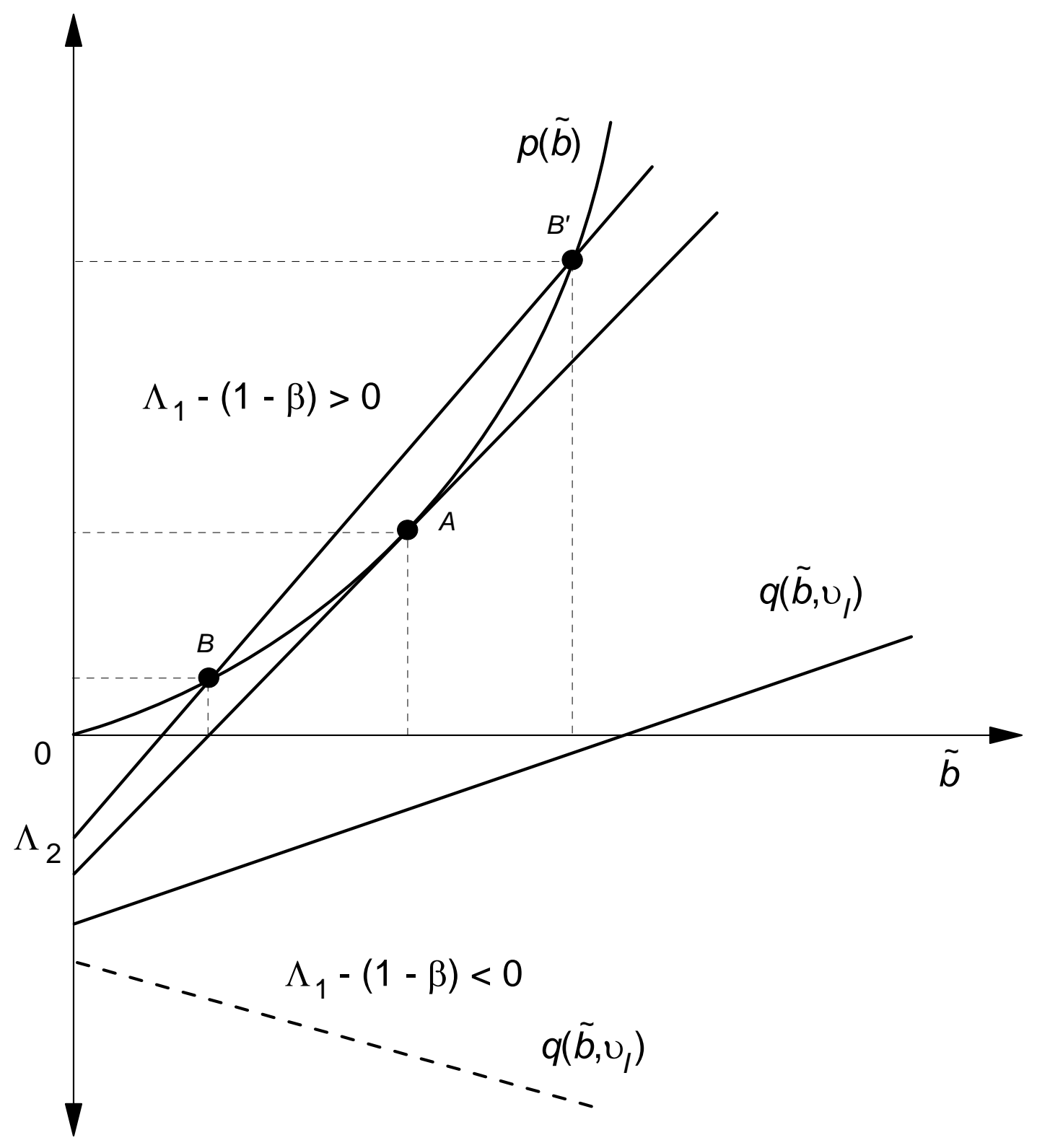


Figure 4

Increase in Investment Spending on Infrastructure

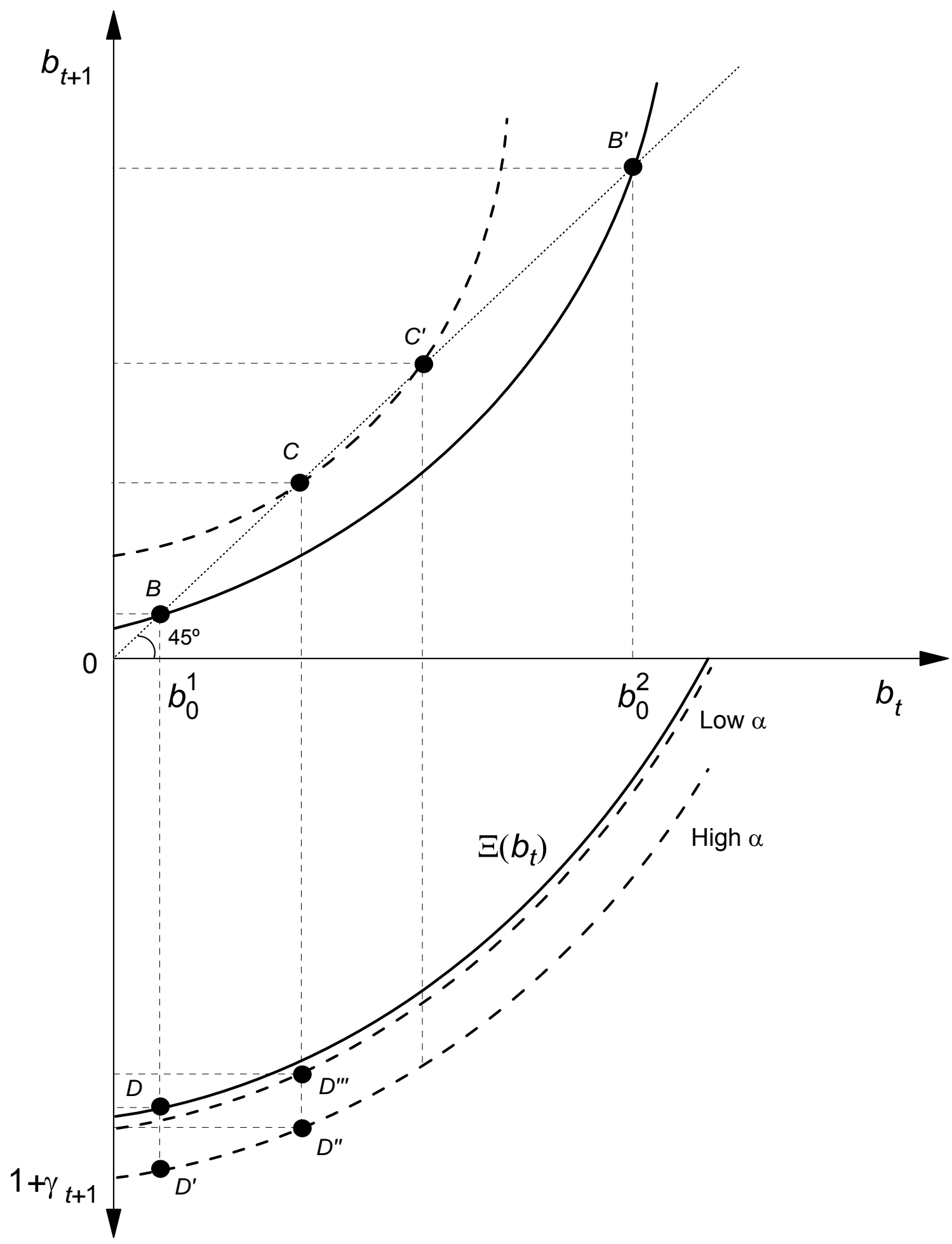


Figure 5

Threshold Value of Public Investment Share with $\chi=0.43$

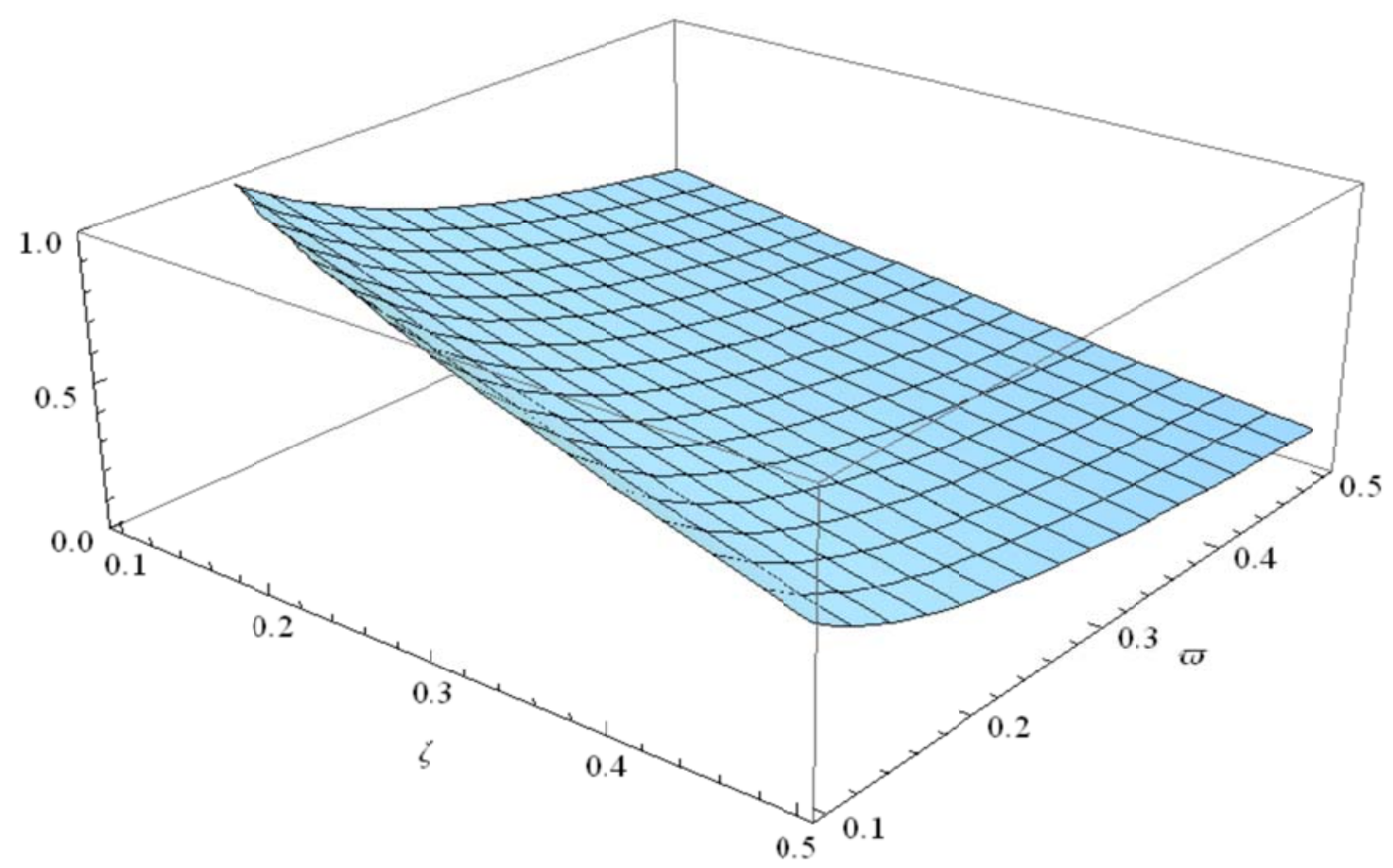

Note: $\zeta$ and $\omega$ are reported on the $\mathrm{x}$-axis and y-axis, respectively, and both parameters are varied between 0.1 and 0.5 . 
Figure 6

Threshold Value of Public Investment Share with $\zeta=0.25$

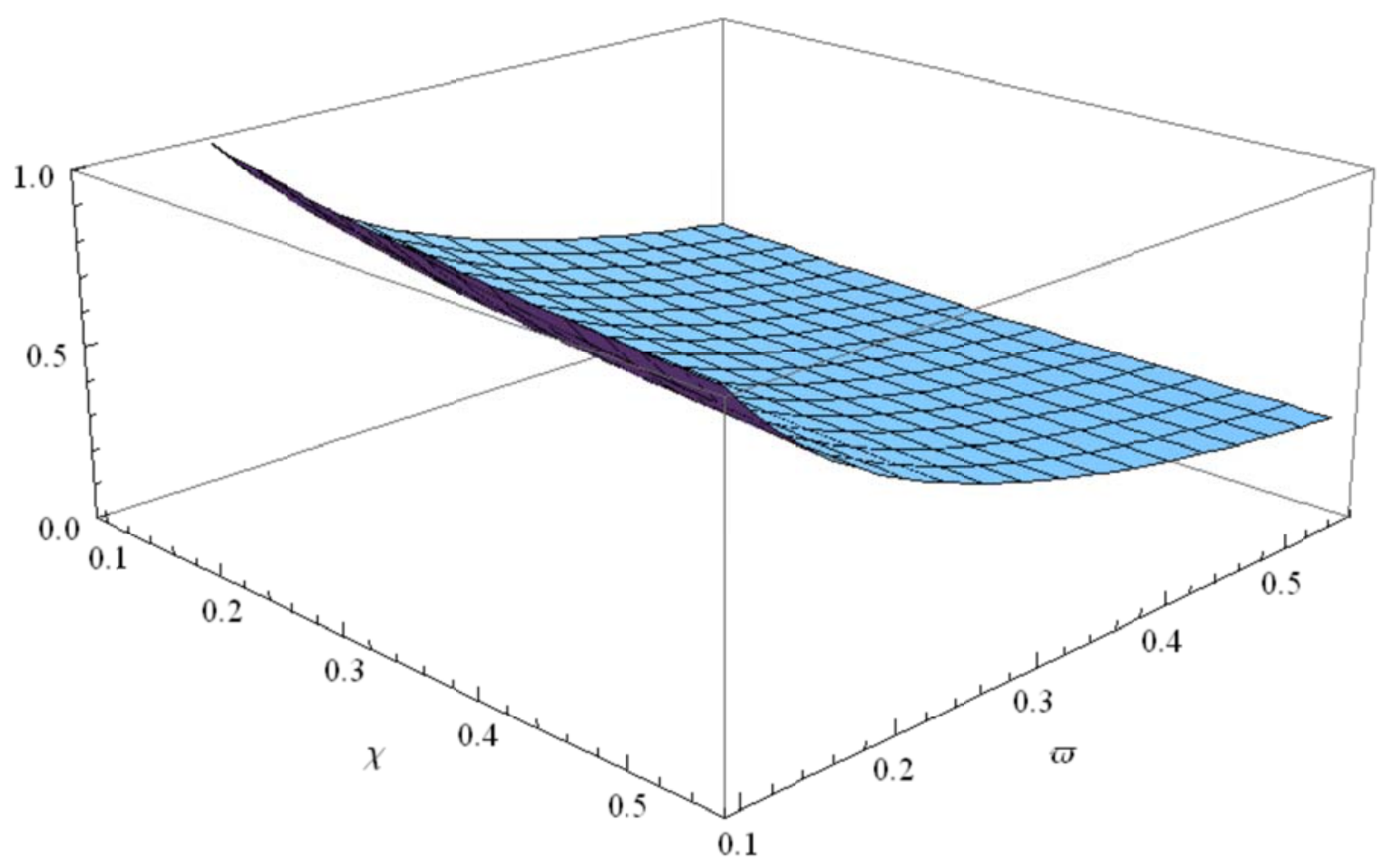

Note: $\chi$ and $\omega$ are reported on the $\mathrm{x}$-axis and $\mathrm{y}$-axis, respectively, and both parameters are varied between 0.1 and 0.5 . 